\title{
التحول الرقمي في عصر البيانات الضخمة مراجعة علمية في في في
}

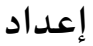 \\ مصطفى محهد إيراهيم الهلالي

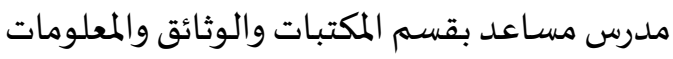 \\ كلية الآداب- جامعة القاهرة
}

E-mail: mostafaelhelalyy@gmail.com

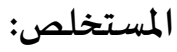

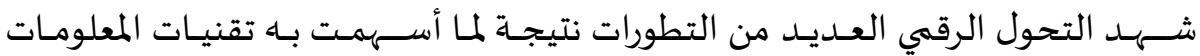

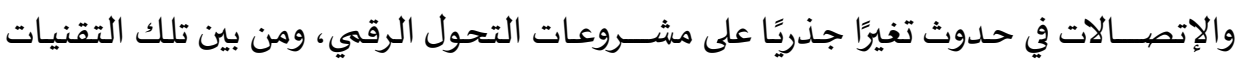

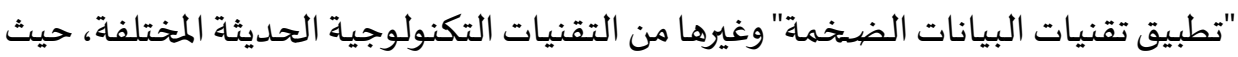

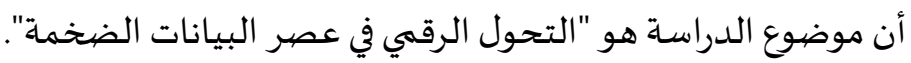

تهدف هذه الدراســة إلى مراجعة أدبيات الإنتاج الفكري المتخصـــص في موضـــوع "التحول

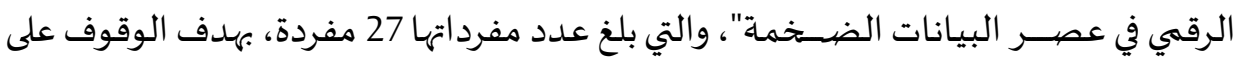
سماته، وتحليل خصائصيه الموضوعياة، والزمنية، والنوعياة، واللغوية. من أبرز ما توصـلت إليه الدراسـة؛ ضــرورة العمل على زيـادة الإنتاج الفكري المكتوب باللغة

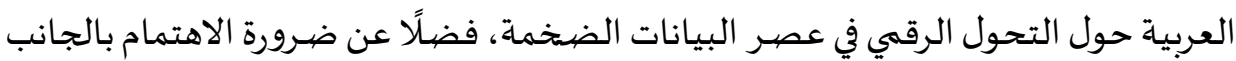

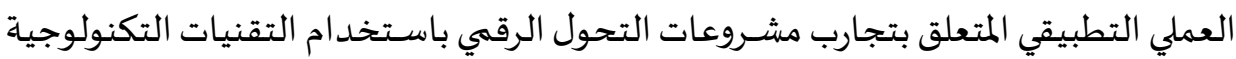
الحديثة بصفة عامة، والاعتماد على تطبيق تقنيات البيانات الضخمة بصفة خلماصية. الكلمات الدالــــــة: التحول الرقمي، الرقمنة، البيانات الضشخمة، التحول الرقهي في عصير

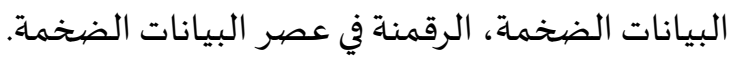


يعد التحول الرقمي اتجاها عالميًا؛ حيث تسعى كل الدول إلى إعداد مشروعات تحول رقمي

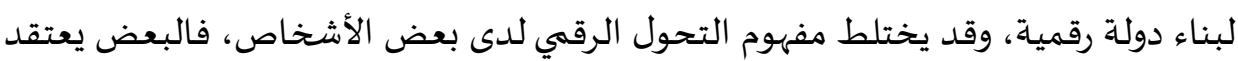

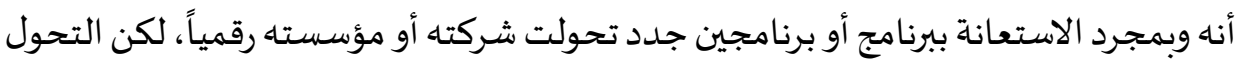

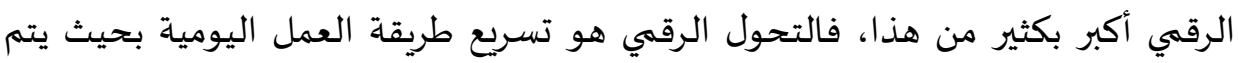

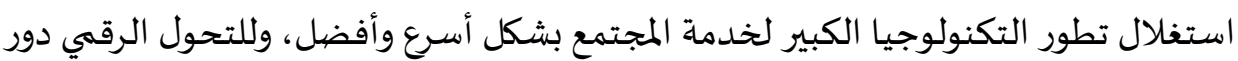
هام في زيادة الكفاءة في خط سير العمل بحيث تقل الأخطاء وتزيد الإنتاجيةــ تعد البيانات أحد أبرز الجوانب لتحقيق التحول الرقمي، وأصبحت المؤسسات على إطلاع

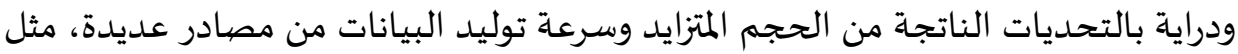

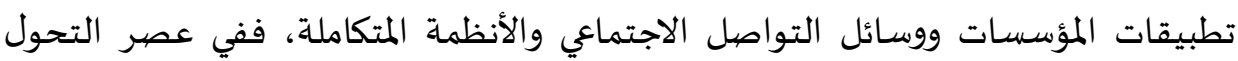

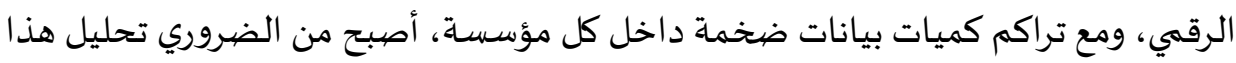

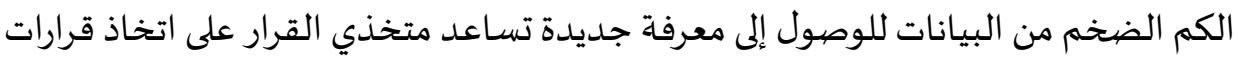
مبنية على معلومات دقيقة.

ويقصد بالبيانات الضخمة؛ تلك البيانات التي تحتوي على عدد كبير جدا من البيانات

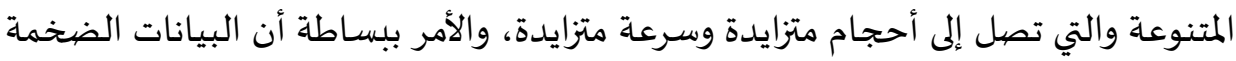

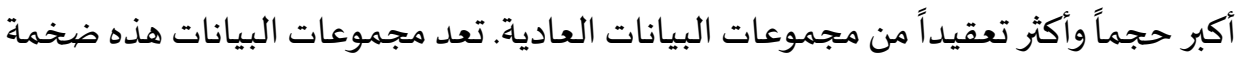

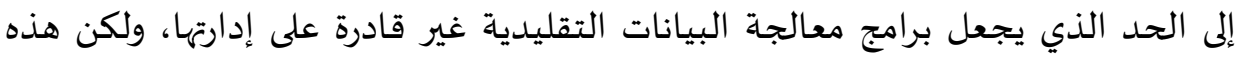

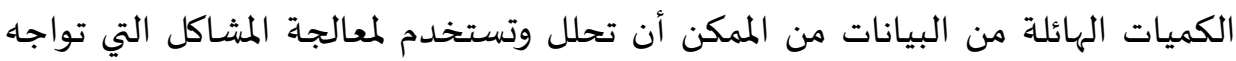
المؤسسات في جميع المجالات.

وتعرض هذه الدراسة مراجعة لأدبيات الإنتاج الفكري في موضوع التحول الرقهي في عصر

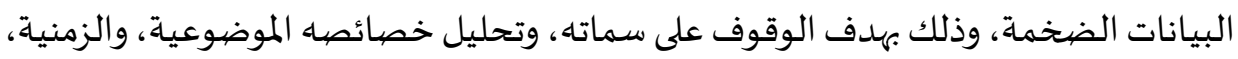
والنوعية، واللغوية، فضلًا عن استخلاص بعض المؤشر ات التي يمكنها المساهمة في تطوير هذا الإنتاج الفكري. 
0 - مصطلحات المراجعة العلمية:

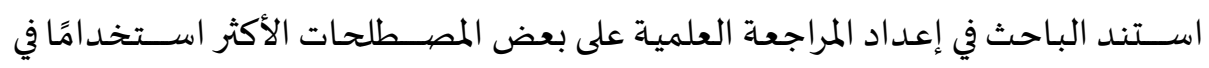

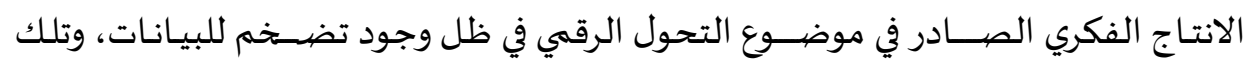

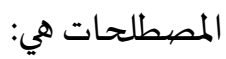

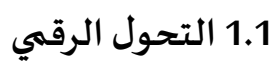

يعرف التحول الرقمي بأنه "إحداث تغييرات في كيفية إدراك وتفكير وتصرفات الأفراد في

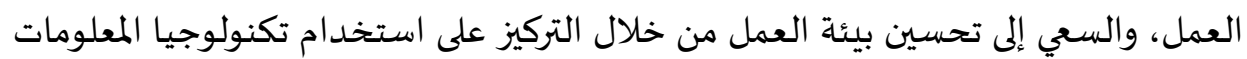

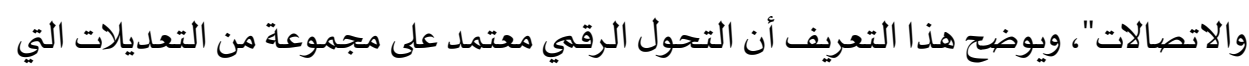

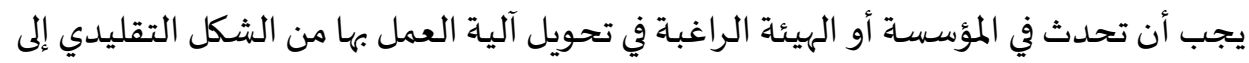

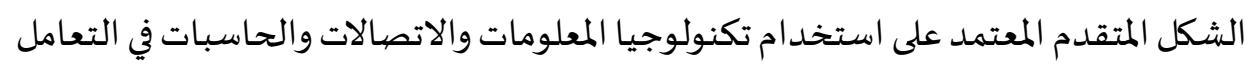
مع المؤسسة سواء من جانب العاملين أو المستفيدين (علي، 2013).

2.1

يقصــد بالرقمنة "عملية تحويل البيانات إلى الشــكل الرقهي باسـتخدام الحاسـبـات الآلية،

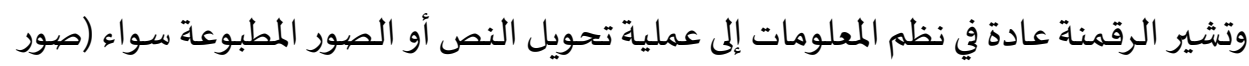

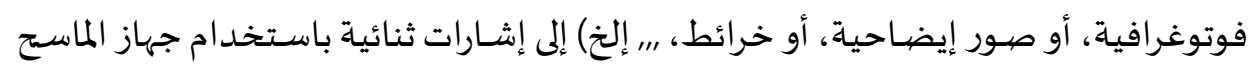

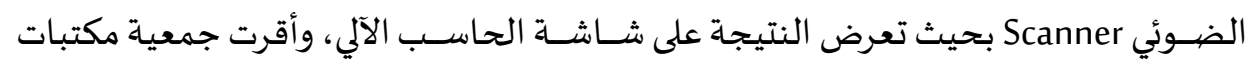

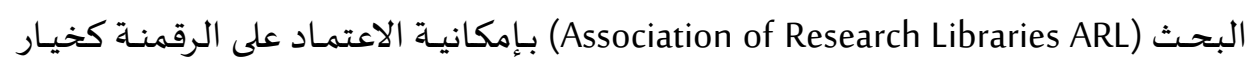
مقبول لحفظ المواد" (Odlis، 2021).

\section{1 البيانات الضخمة}

هي "أنماط البيـانات التي تتخطى قـدرات أنظمة ومســـودعات وقواعد البيانات التقليدية

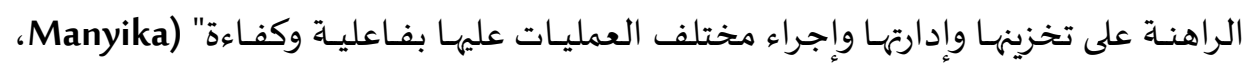




\section{1. - أهداف المراجعة العلمية:}

تسعى هذه المراجعة العلمية إلى توضيح الصيورة الكاملة للإنتاج الفكري العربي والأجنبي في

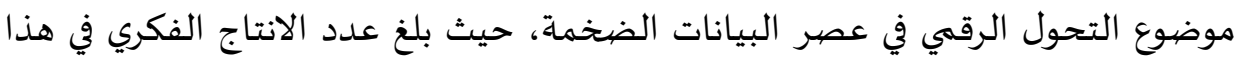
الموضوع (27) مفردة، وذلك من خلال تحقيق الأهداف التالية:

1) الإحاطة بما تناوله الإنتاج الفكري المتخصص عن عمليات التحول الرقي في عصر

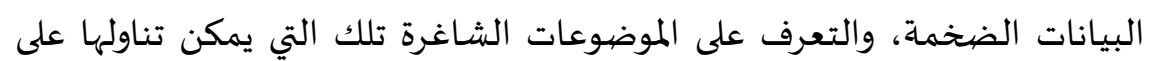

$$
\text { مستوى الدراسات العلمية. }
$$

2) التعرف على سمات وخصائص هذا الرصيد من الإنتاج الفكري الموضوعية، والزمنية،

$$
\text { واللغوية، والنوعياة. }
$$

التعرف على إتجاهات هذا الإنتاج الفكري من حيث مدى الإهتمام بالجوانب النظرية،

$$
\text { والجوانب التطبيقية. }
$$

\section{2. - 2. - حدود المراجعة العلمية}

\section{الحدود الموضوعية واللغوية:}

تناولت المراجعة العلمية الإنتاج الفكري لقضــــــة التحول الرقهي وارتباطها بالتقنيات

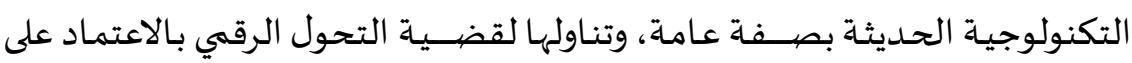
تقنيات البيانات الضخمة بصفة خاصية، المنشور باللغة العربية والإنجليزية فقط.

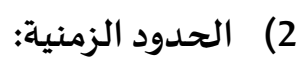

غطت المراجعة العلميـة الإنتاج الفكري الصــادر منذ عام 2015م (بـايـات الاهتمام بالإنتاج الفكري عن الموضوع) وحتى عام 2021م (تاريخ إنتهاء الدراسـة).

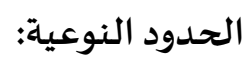

تنـاولت المراجعـة العلمية الإنتاج الفكري من الرســائل الجـامعيـة، والمقالات العلمية،

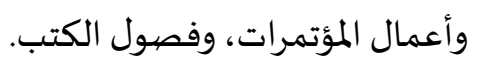




$$
\begin{aligned}
& \text { 3. المنهج المتبع في إعداد المراجعة العلمية } \\
& 1.4 \text { استر اتيجية مسح مفردات الإنتاج الفكري: }
\end{aligned}
$$

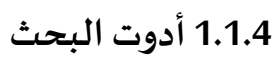

قام الباحث بعمل مسيح شـامل للإنتاج الفكري المنشـور حول موضـوع الدر اسـة العربي منهـ

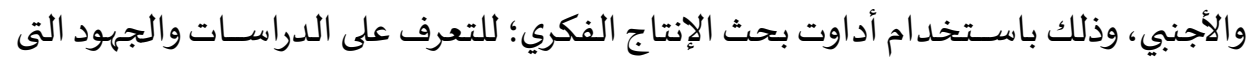

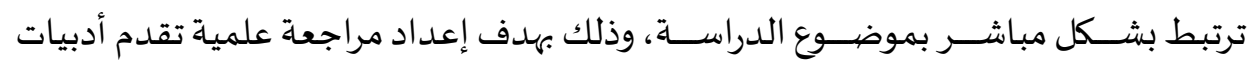

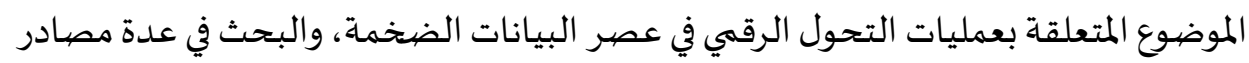

$$
\begin{aligned}
& \text { سواء باللغة العربية أو اللغة الإنجليزية، وهي: } \\
& \text { أدلة وقواعد بيانات الانتاج الفكري العربي: } \\
& \text { فهرس اتحاد مكتبات الجامعات المصرية، متاح على: }
\end{aligned}
$$

http://srv3.eulc.edu.eg/eulc_v5/libraries/start.aspx

قاعدة بيانات مقالات الدوريات التي تصــــر عن البوابة العربية للمكتبات

$$
\text { والمعلومات على الرابط التالي: }
$$

http://journal.cybrarians.info/

قاعدة بيانات الهادى للانتاج الفكري المتاحة من خلال موقع الاتحاد العربى

$$
\text { للمكتبات والمعلومات على الرابط التالي: }
$$

https://arab-afli.org/main/

قواعد البيانات العبية المتاحة من خلال بنك المعرفة المصري، مثل: قواعد

بيانات دار المنظومة، وقواعد بيانات العبيكان الرقمية على الرابط التالي:

https://www.ekb.eg/web/guest/resources?sourcesLang=ar

$$
\text { أدلة وقواعد بيانات الانتاج الفكري الأجنبي: }
$$

اعتمد الباحث على قواعد البيانات المتاحة من خلال بنك المعرفة المصــري في البحث عن

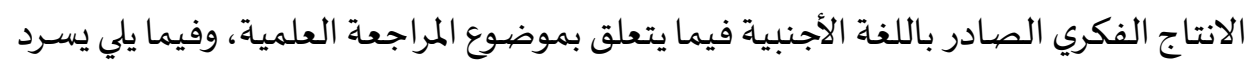

$$
\text { الباحث قواعد البيانات التي قام بالبحث فيها: }
$$




\section{.Ebsco (Lista) (1 \\ .Elseveir (Science Direct) $\quad(2$ \\ .Emerald (3 \\ .IEEE (4 \\ .Proquest (5 \\ .Sage $(6$ \\ .Wiley (7 \\ محركات البحث العالمية:}

اعتمد الباحث في إعداد المراجعة العلمية على أشهر محركات البحث العالمية مثل:Google,

.AltaVista, Yahoo, Google Scholar

$$
\text { 2.1.4 استر اتيجية البحث }
$$

اســتخدم الباحث مجموعة من المصــطلحات والكلمات الد الة للحصــــل على أكبر عدد من الإنتاج الفكري ذات العلاقة بموضوع الدراسـة، والمصطلحات المستخدماتهة هي:

باللغة الإنجليزية

باللغة العربية

Digital Transformation

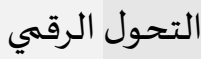

Digitization

Big Data الرقمنة

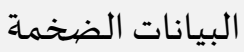

وقد إلتزم الباحث في معالجة الإنتاج الفكري المنتقى لتحقيق أهداف هذه المراجعة العلمية

إتسـام المراجعة العلمية بأقصى درجات الإنتقاء لما توافر للباحث من دراسـات علمية

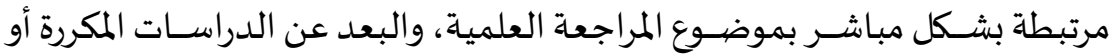
غير المرتبطة مباشرة بالموضيوع. مبن. 
2) جاء تصنيف هذا الإنتاج لعدة موضوعات فرعية، حيث نُظمت المراجعة العلمية وفقا

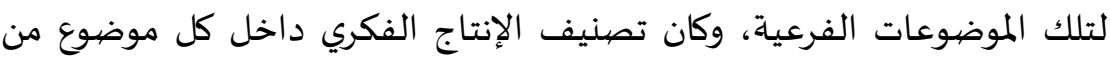

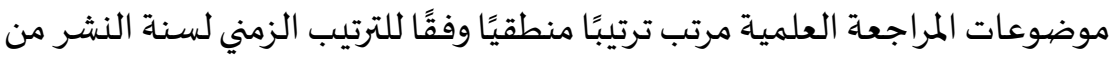

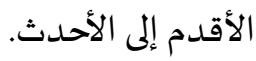
3) انتهت المراجعة العلمية بتقديم مجموعة من الملاحظات التي تم استنتاجها بعد المدات

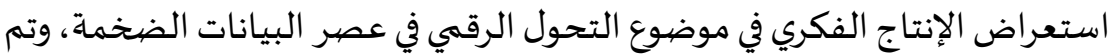
استخلاص بعض المؤشرات التي يمكنها المساهمة في تطوير هذا الإنتاج الفكري. 3.1.4 نتائج مسح الإنتاج الفكري:

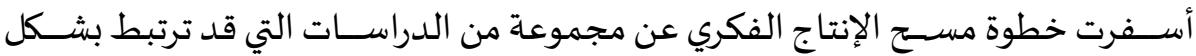

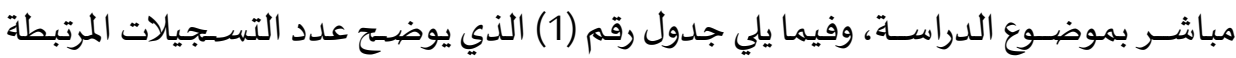
ببعض المصــطلحات التي اســتخدمت لمراجعة أدبيات الموضـــوع عبر قواعد البيانات العالمية المتاحة من خلال بنك المعرفة المصري.

جدول رقم (1) عدد التسجيلات المرتبطة مباشرة بمصطلحات الدراسة في قواعد

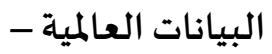

\begin{tabular}{|c|c|c|c|c|c|c|c|c|c|}
\hline Database & EBSCO & $\begin{array}{l}\text { Elseveir } \\
\text { (Science } \\
\text { Direct) }\end{array}$ & Emerald & IEEE & ProQuest & Sage & Wiley & المجموع| & المئوية النسبة \\
\hline $\begin{array}{c}\text { Digital } \\
\text { Transformation }\end{array}$ & 597 & 2680 & 2000 & 1119 & 303 & 715 & 1014 & 8428 & $2 \%$ \\
\hline Digitization & 7877 & 171952 & 5000 & 3466 & 389 & 5865 & 12644 & 207193 & $48.7 \%$ \\
\hline Big Data & 85639 & 40151 & 8000 & 45986 & 5645 & 7969 & 15604 & 208994 & $49.1 \%$ \\
\hline $\begin{array}{c}\text { Digital } \\
\text { Transformation } \\
\text { AND } \\
\text { Big Data }\end{array}$ & 24 & 79 & 56 & 23 & 45 & 36 & 47 & 310 & $0.1 \%$ \\
\hline $\begin{array}{c}\text { Digitization } \\
\text { AND } \\
\text { Big Data }\end{array}$ & 38 & 98 & 74 & 52 & 103 & 43 & 67 & 475 & $0.1 \%$ \\
\hline المجموع & 94283 & 215520 & 15403 & 50800 & 8820 & 15237 & 30000 & \multirow{2}{*}{\multicolumn{2}{|c|}{425395}} \\
\hline النسببة المئوية & $22 \%$ & $50 \%$ & $4 \%$ & $12 \%$ & $2 \%$ & $3 \%$ & $7 \%$ & & \\
\hline
\end{tabular}




$$
\text { التعليق على نتائج مسح الإنتاج الفكري: }
$$

يتضح من خلال استعراض نتائج البحث في الجدول السابق (1) أن أكثر المصطلحات

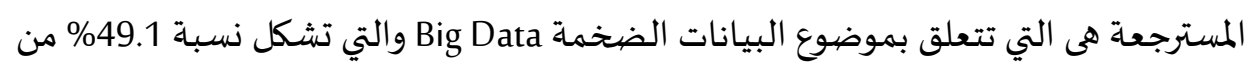

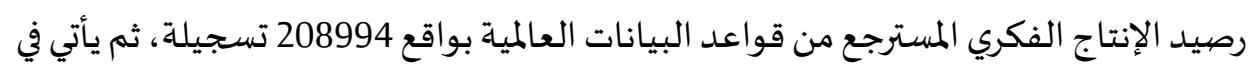

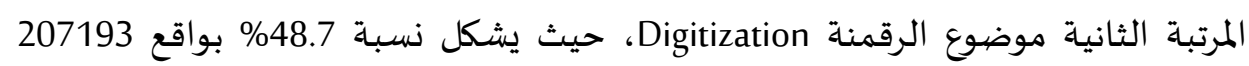

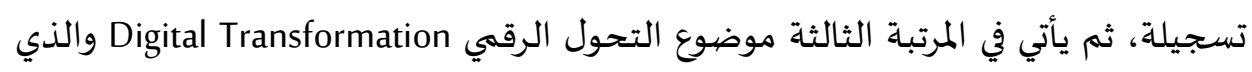

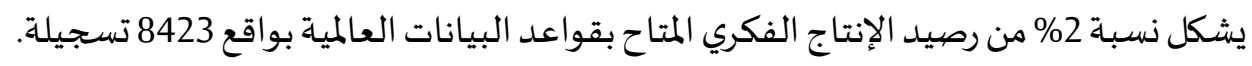
أما بالنسبة لربط المصطلحات ببعضها البعض للوصهول إلى الإنتاج الفكري ذات العلاقة

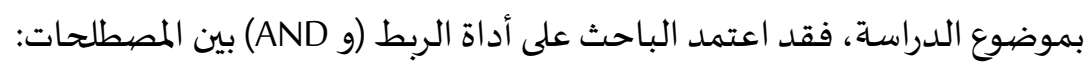

$$
\begin{aligned}
& \text { التحول الرقبي (و) البيانات } \\
& \text { الضخمة }
\end{aligned}
$$

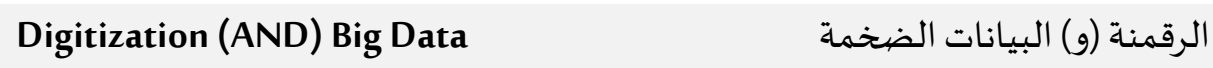

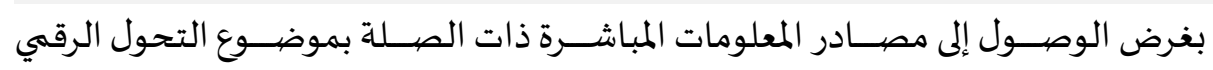

$$
\text { والرقمنة في عصر البيانات الضخمة. لوضئ. }
$$

4. الموضـــوعـات التي حظيت بـاهتمـام الإنتـاج الفكري عن التحول الرقهي في عصـر

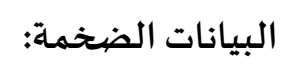

قام الباحث بمســح الإنتـاج الفكري حول الموضــــوع نتج عنه (27) مفردة مرتبطة بشــكل

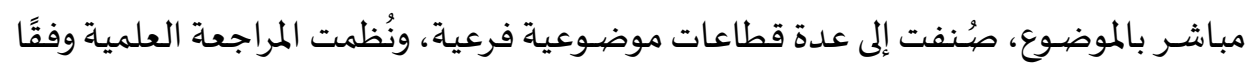

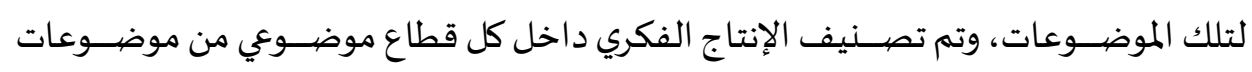

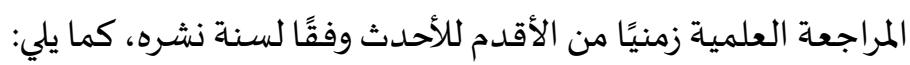

$$
1.5 \text { تطبيق تقنيات البيانات الضخمة في عمليات التحول الرقهي: }
$$

عرض كل من (Loebbecke \& Picot) في دراستهما عام 2015 بعض الآليات والطرق التي يمكن إتباعها للقيام بعمليات الرقمنة داخل المؤسسات في ظل التسارع المستمر لعمليات 
الرقمنة وتحليلات البيانات الضخمة، وتحديد الآثار المحتملة للرقمنة وتحليلات البيانات

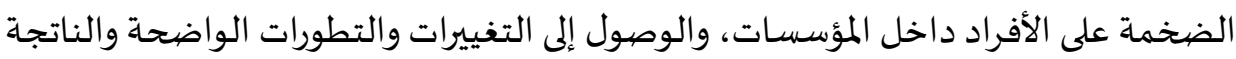
عن عمليات الرقمنة داخل المؤسسات. كما كشف (علي فتحي) في أطروحة الماجستير التي أعدها عام 2016 بقسم المكتبات والوثائق

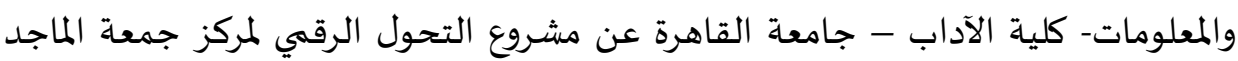

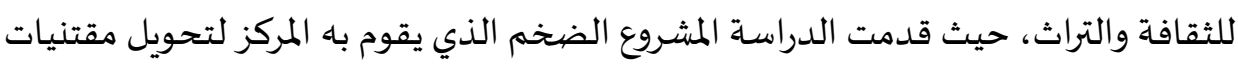
المركز من شكلها المطبوع إلى الشكل الرقهي، مع مراعاة ضخامة حجم البيانات المتاحة داخل

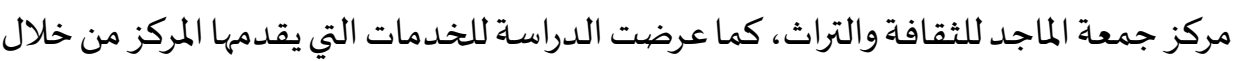
المحتوى الرقمي الذي يملكاء.

وأوضح (Șerban) في دراسته عام 2017 فكرة تعامل الشركات في وقتنا الحاضر مع كميات

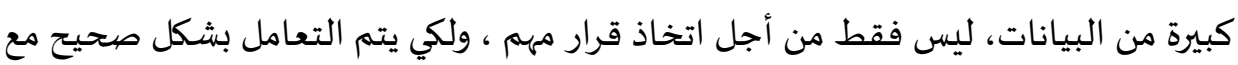

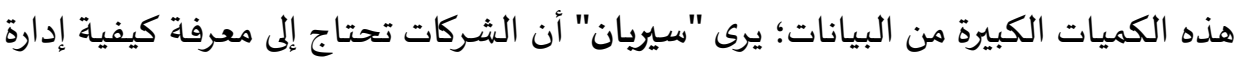

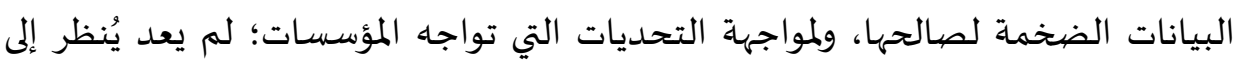

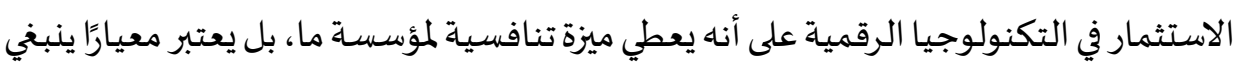
الاعتماد عليه لنجاح المؤسسة في التعامل مع ضخدامة بياناتها. وفي هذا الصدد قام كل من (Sarkar \& Wu \& Hossin) بإعداد دراسة عام 2018 ناقشت فكرة التحويل في الإدارات داخل المؤسسات من التعامل التقليدي إلى التعامل الذكي المبني على من دألى

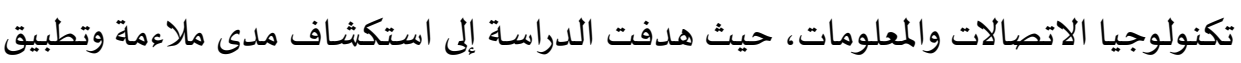

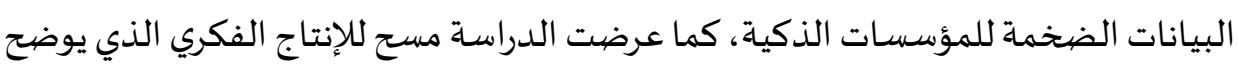

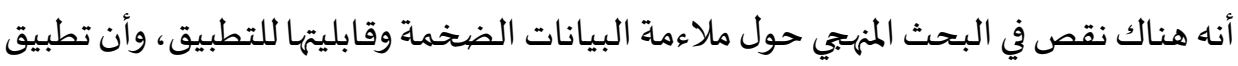

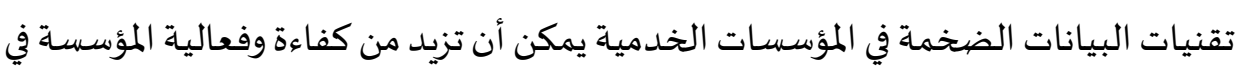

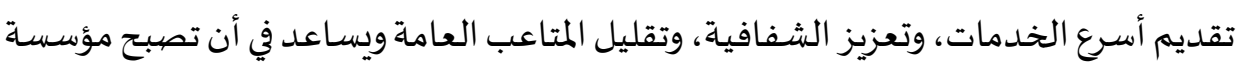

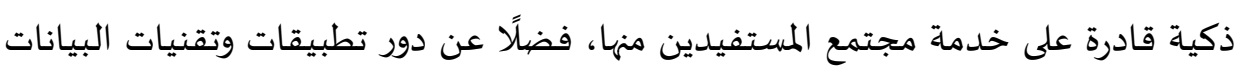

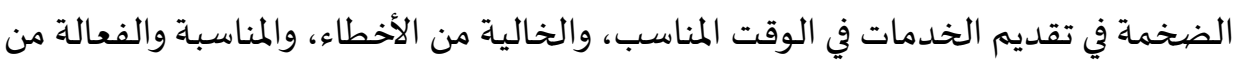
حيث التكلفة للمواطنين مما يؤدي إلى التنمية الاقتصادية المستدامة للبلد. 
كما رأى كل من (Johanes \& Thille) في دراسـهما عام 2019 أن الأبحاث التي تم نشـرها في

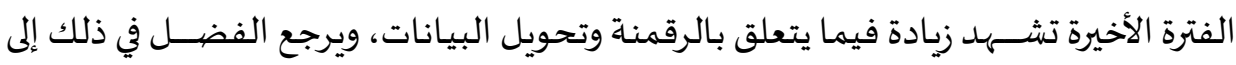

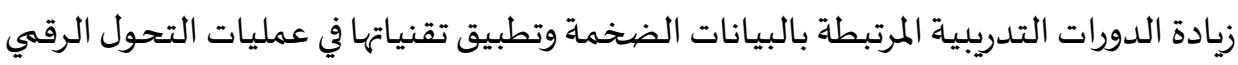

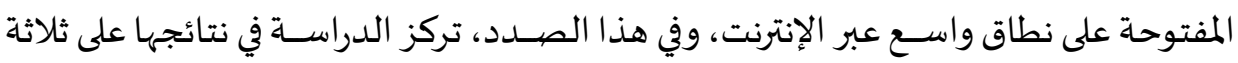

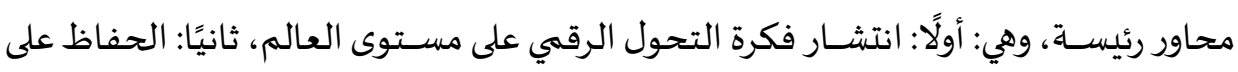

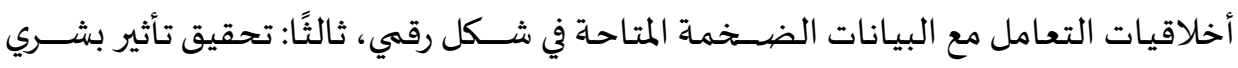

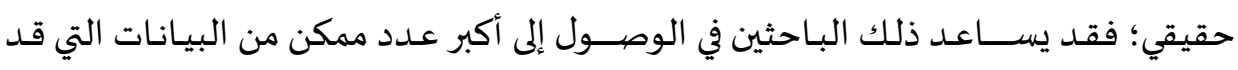
يحتاجون إليها في أبحاثهم ودراستهم مع مراعاة الاستخدام الأمثل لتلك البيانات.

وناقش كل من ( Thamjaroenporn \& Achalakul) في دراستهما عام 2020 قضية ارتباط التحول الرقمي بمركزية الحكومات، حيث سعت الدراسة إلى تقديم حلول رقمية مبتكرة

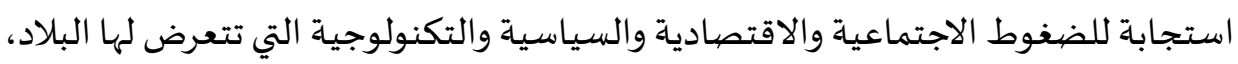

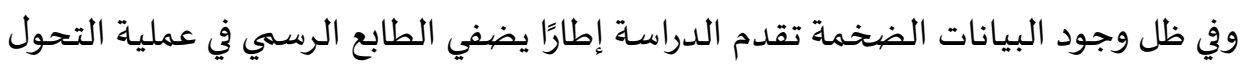

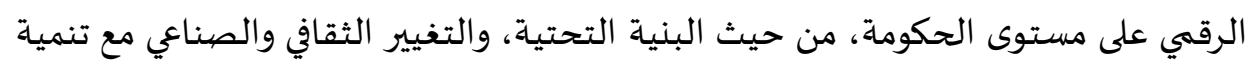

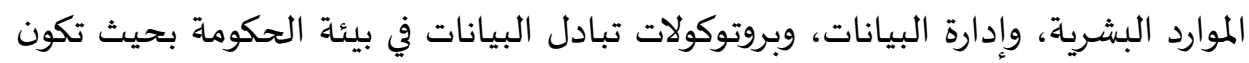

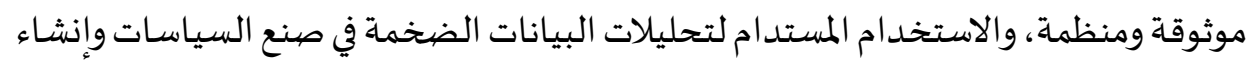

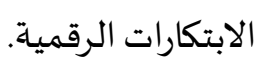

وفي نفس العام، توصل كل من (Liu \& Wang \& Zhang) في دراستهم عام 2020 إلى دور البيانات الضخمة في تعزيز عملية التحول الرقمي بشكل أفضل، واقترح المؤلفون إطارًا نظريًا

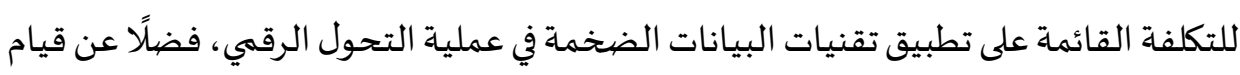

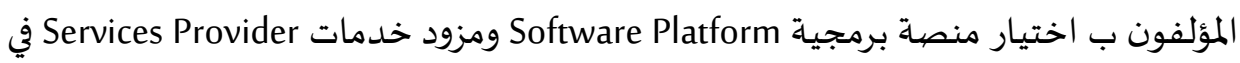

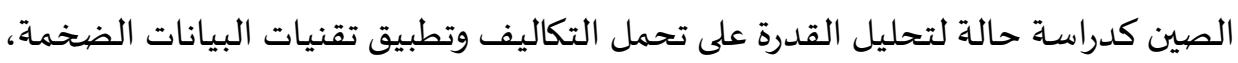
كما تقدم الدراسة نموذجًا لكيفية تفيذ مشروعات التحول الرقهي عن طريق تطبيق تقنيات البيانات الضخمة. كما كشف كل من (El Hilali \& El Mansour \& Janati) في دراستهم عام 2020 عن العالم الذي أصبحت فيه البيانات الضخمة ضرورية لضمان نجاح الشركات، حيث جاء التحول 
الرقمي لمساعدة الشركات على التحول نحو الأعمال التجارية الرقمية وقبول التغييرات في الهيكل

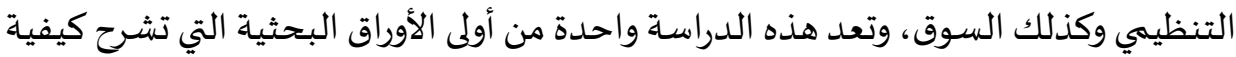

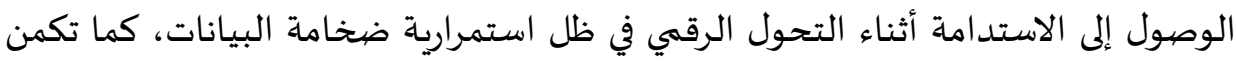

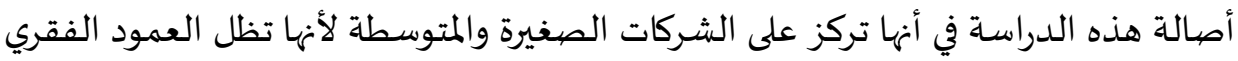
للاقتصاد المغربي. وناقش (Ratten) في الفصل السابع من كتابه الصادر عام 2020 بعنوان (التحول الرقمي في الرياضية ووسائل التواصل الاجتماعي Digital Transformation in Sport and Social Media

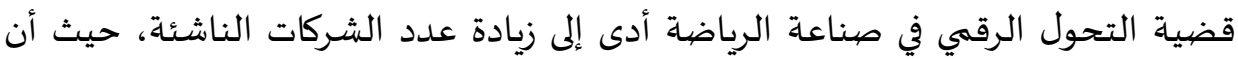

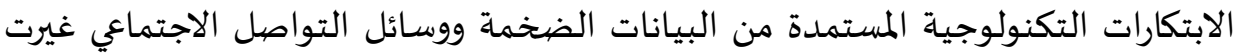

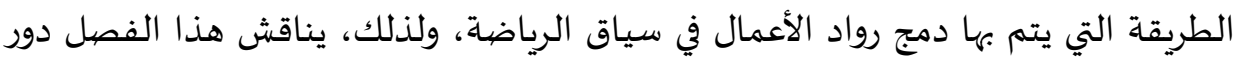
الرقمنة في تغيير نماذج الأعمال الحالية وتعزيز نظام بيئي لريادة الأعمال في سياق الرياض فياضية. كما استعرض كل من (Abad \& Gonzalez \& Infante \& Ruiperez) في دراستههم عام 2020

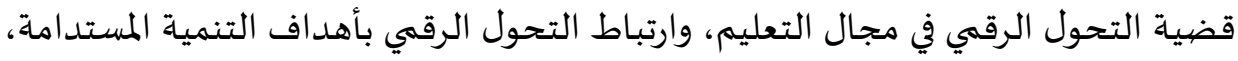

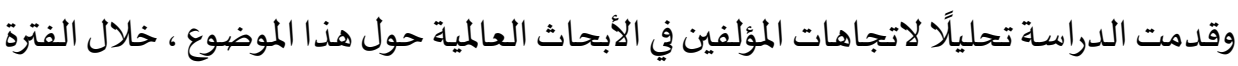

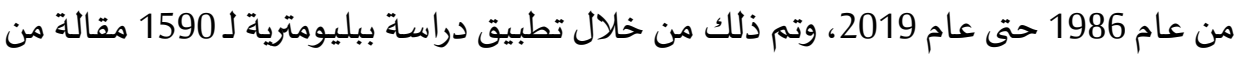
قاعدة بيانات Scopus، حيث كانت النتيجة أن هناك زيادة حول حلف الإنتاجية العلمية للمؤلفين

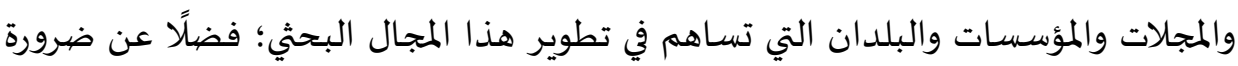

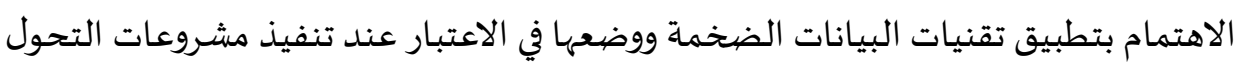
الرقمي. تعد الدراسة التي أعدها كل من (Sesana \& Bardelli) عام 2021 من أحدث الدراسات التي

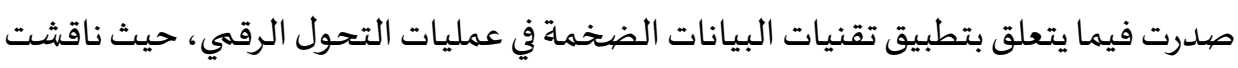

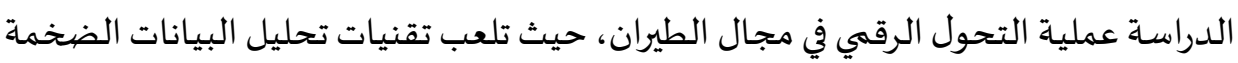
دورًا مركزيًا في جمع وتخزين التحليلات وتقديم الأدلة حول ما حدث أنداء أثناء الرحلة. وقد حاول (نصر) في أطروحة الدكتوراه التي أعدها بقسم إدارة الأعمال - كلية التجارة -

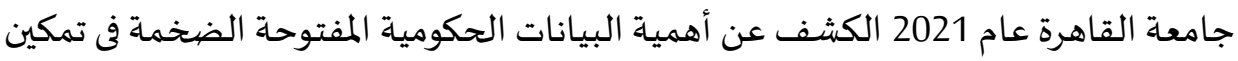


و تعزيز التحول الرقمي والانتقال من مفهوم الحكومة الإلكترونية إلى مفهوم أكثر تطورا وحداثة

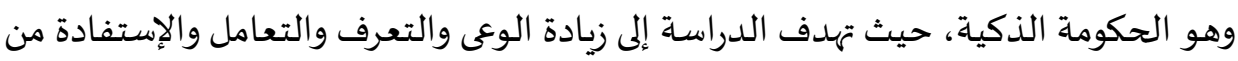

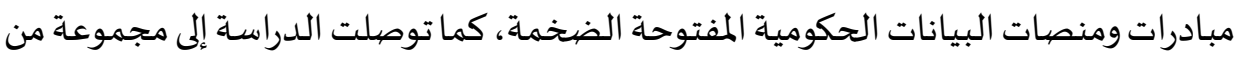

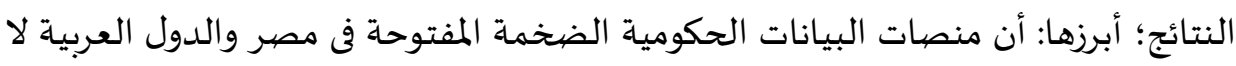
تزال تحتاج لمزيد من التطوير والتنوع والإثراء والتفاعل بين المواطنين و الحكومة.

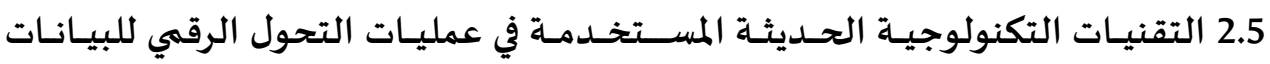
الضخمة:

أشار (Huang، 2017) في دراسته عام 2017 إلى أننا أصبحنا في عصرالتغييرات العظيمة،

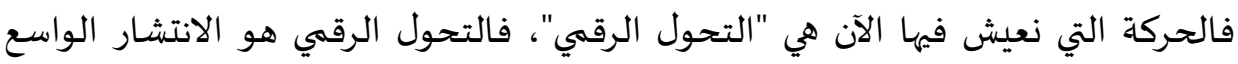

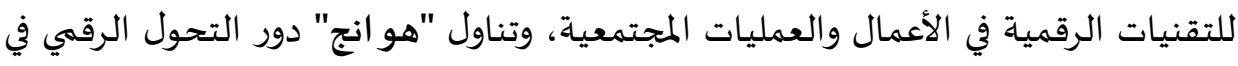

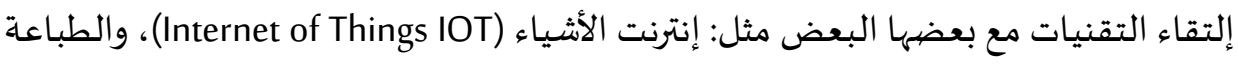

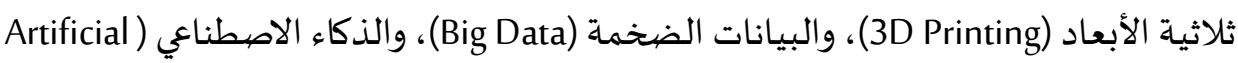

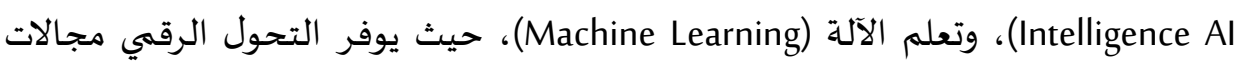
خصببة لمزيد من التطوير لهذه التقنيات، والأهم من ذلك، نمو التقنيات الجديدة والأعمال

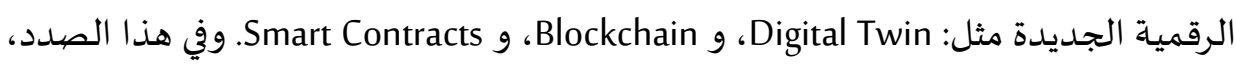

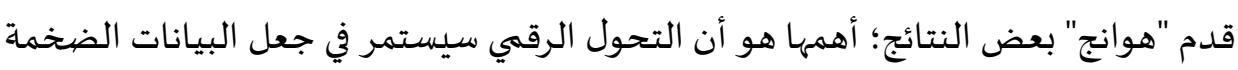
تزداد أكثر وأكثر.

وتناول كل من (Ruchi \& Srinath) في دراستهما عام 2018 دور التنقيب في البيانات Data

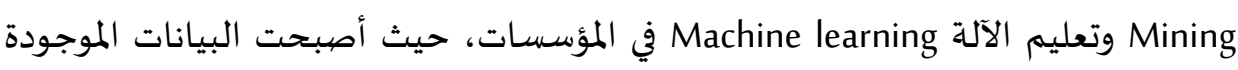

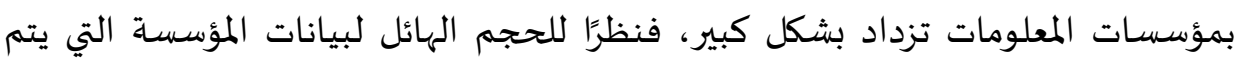

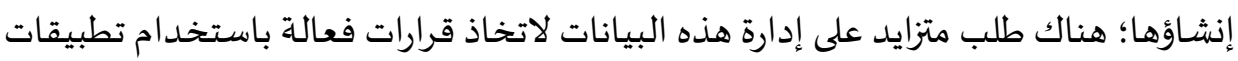

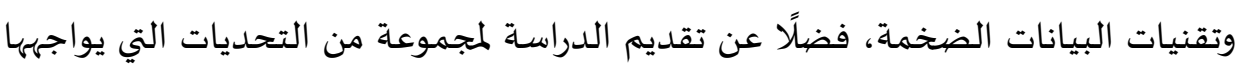

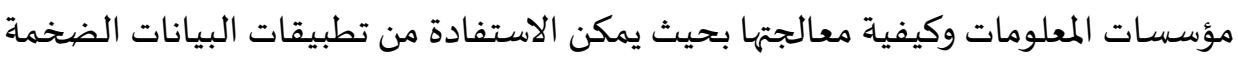

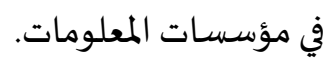


وفي نفس العام، استعرض كل من (Mendonca \& Andrade \& Sousa) في دراستهم عام

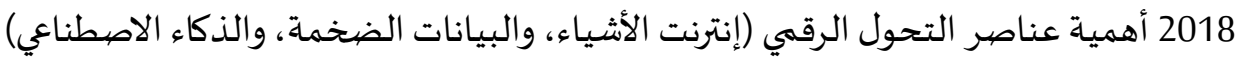
كدعم لعمليات التحول الرقمي التي تتم بالمؤسسات الموجودة في عاصيمة البرازيل (برازيليا)،

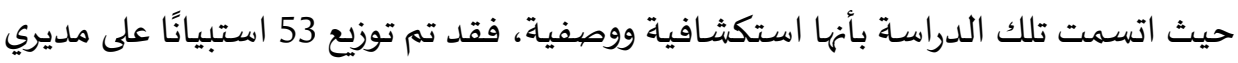
الأعمال ومديري تكنولوجيا المعلومات؛ وقد نتج عن تحليل تلك الاستبيانات تحديد أنها في تصور

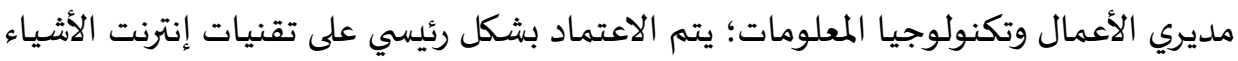

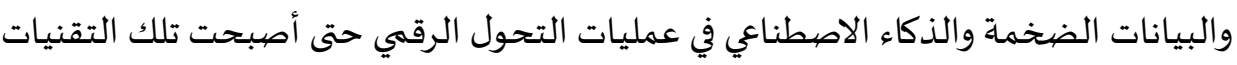
جزء من عمليات التحول الرقهي، وأصبحت تندرج تحت مسمى (عناصر التحول الرقهي). وقد أشار (Huang) مرة أخرى في دراسته عام 2019 إلى فكرة الانتشار السريع للتقنيات

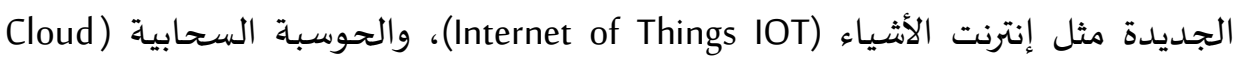

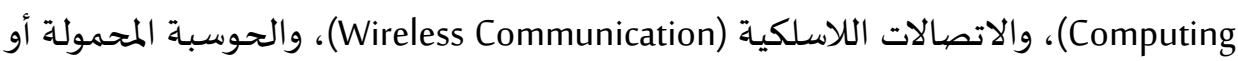
المتنقلة (Mobile Computing)، والبيانات الضخمة (Big Data)، والذكاء الاصطناعي والتهاء (Machine Learning) بما في ذلك تعليم الآلة (Artificial Intelligence Al)

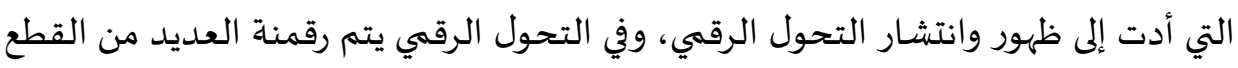

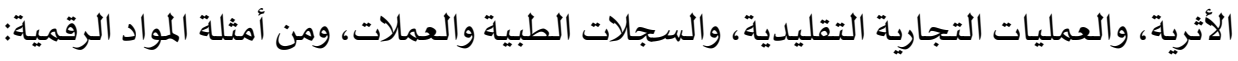

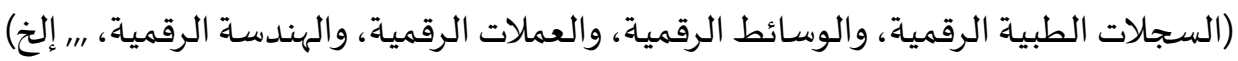

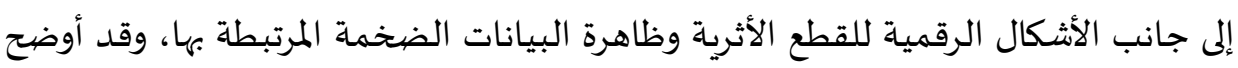

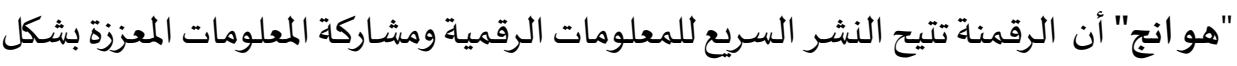

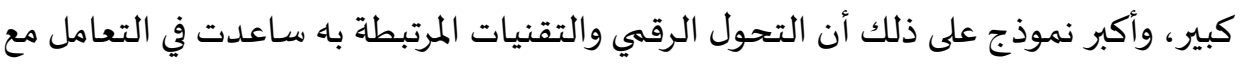
جائحة Covid-19 بكفاءة وفاعلية والتغلب على تحدياتها. كما كشف كل من (Miklosik \& Evans) في دراستهما عام 2020 عن تأثير البيانات الضخمة وتعليم الآلة (Machine Learning ML) على التحول الرقهي لصناعة التسويق والتحديات التي

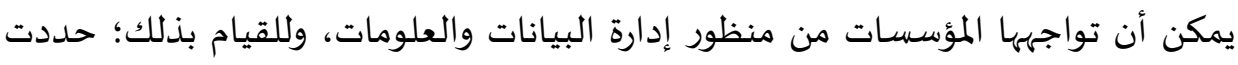

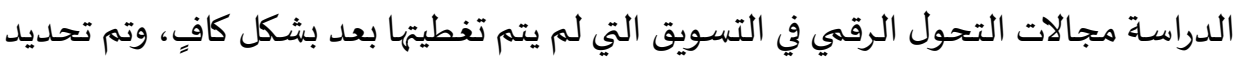
تلك المجالات من خلال البحث في مجموعة من قواعد البيانات العالمية، وهم: (Web of 
science, Scopus, ProQuest, Emerald, ScienceDirect محتملة للبحث في المستقبل في مجال استخدام البيانات الضخمة وتطبيق التقنيات القائمة على تعليم الآلة في مجال التسويق.

وفي نفس العام، استطاع مجموعة من الباحثين (Maria Irene Prete،Andrea Sestino، Gianluigi Guido ،Luigi Piper والبيانات الضخمة في التعامل مع البيئة الرقمية في إدارة المؤسسات فيما يتعلق بعمليات

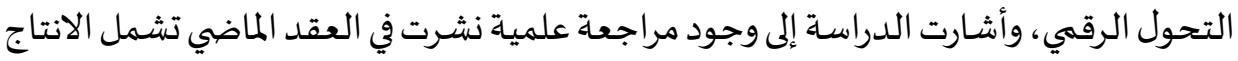
الفكري الصادر منذ عام (2008 : 2019)؛ والتي حللت كل من إنترنت الأشياء والبيانات

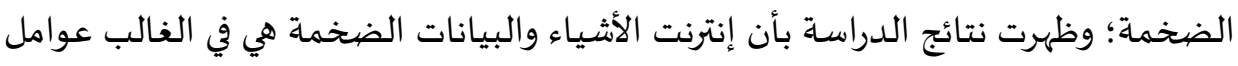

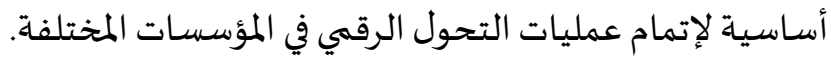
واستطاع كل من (مقدمي \& بن عمر) في دراستهم عام 2020 الكشف عن ثورة البيانات

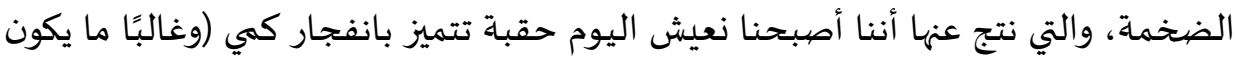

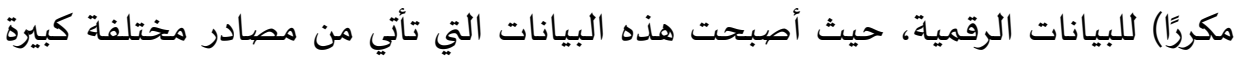

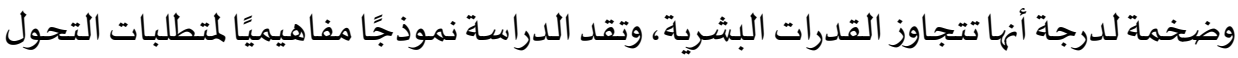

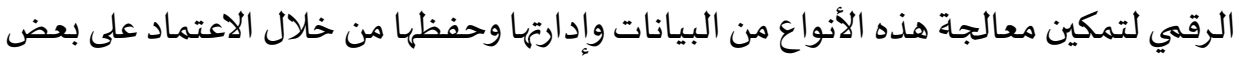

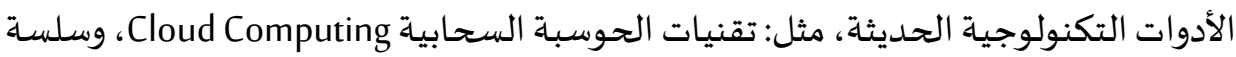

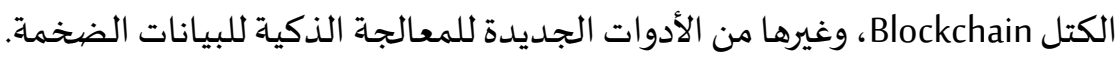
كما أوضح (Khanna) في الفصل الخامس بكتابه الصادر عام 2020 بعنوان "تطبيقات Applications of Big Data تحليلات البيانات الضخمة: هدية لصناعة المواد الغذائية "Analytics: a boon for the Food Industry

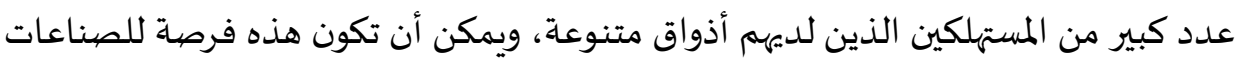

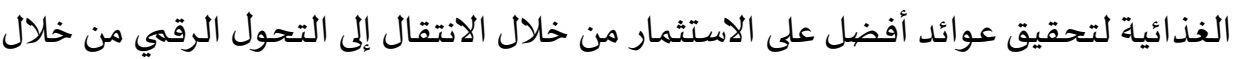

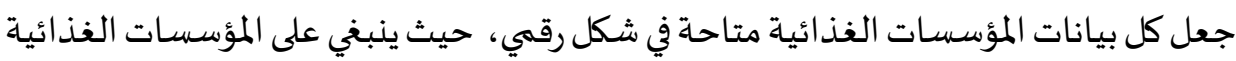

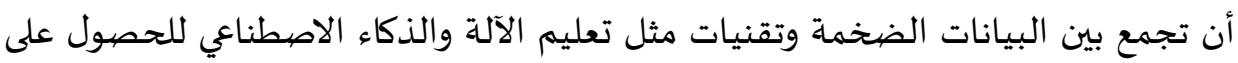
تجارب أسرع وأكثر تخصيصًا. 
تتمثل أحدث الدراسات في موضوع استخدام التقنيات التكنولوجية الحديثة في عمليات

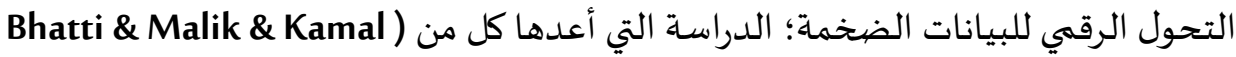
\&Aamir \&Alaali \&Ullah

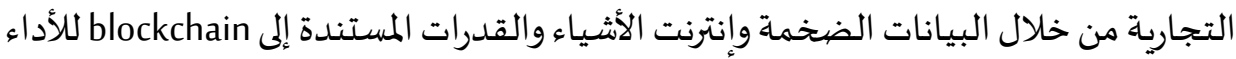
الاستراتيجي العام داخل قطاع الاتصالات في الصين، حيث لعبت قدرات تحليلات البيات البيانات

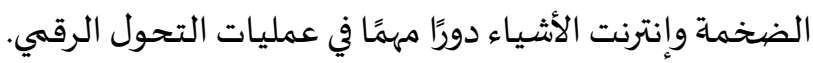

كما أوضح كل من (Feroz \& Zo \& Chiravuri) في دراستهم عام 2021 دور التحول الرقمي في إحداث اضطرابات غير مسبوقة في المجتمع والصناعة والمؤسسات التي حفزها التقدم في داتهات

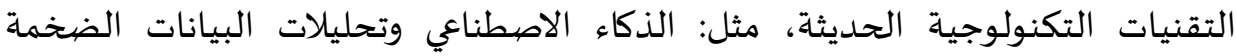

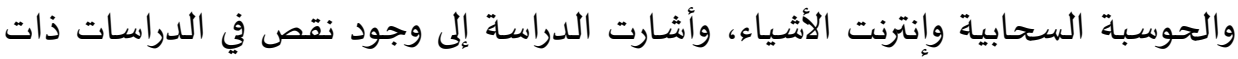

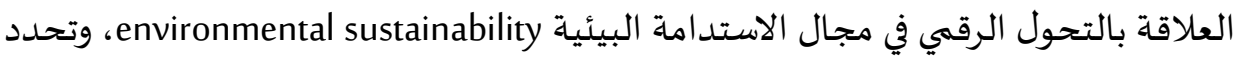
الدراسة تلك الاضطرابات التي يقودها التحول الرقهي في مجال الاستدامة البيئية من خلال مراجعة علمية للأدبيات الموضوع.

3.5 التحديات التي تواجه تطبيق تقنيات البيانات الضخمة في عمليات التحول الرقهي: تناول كل من (Ordonez \& Labra) في دراستهما عام 2019 ارتباط انتشـار مفهوم البيانات

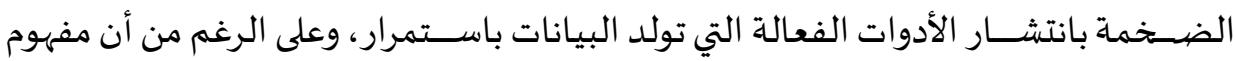

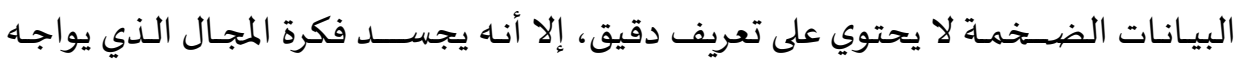

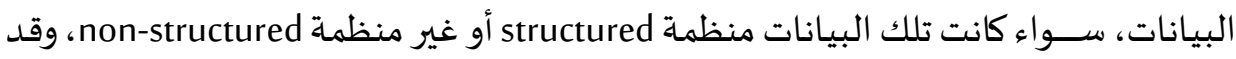

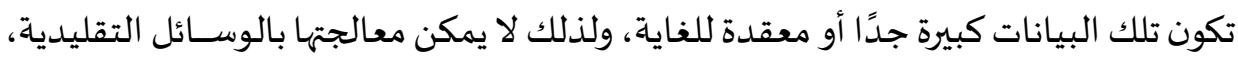

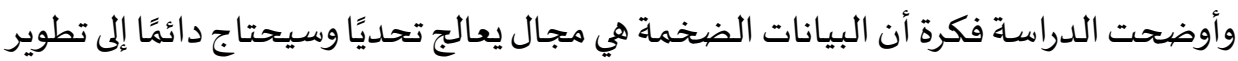

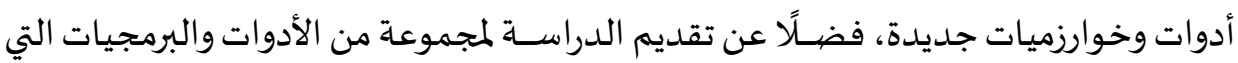

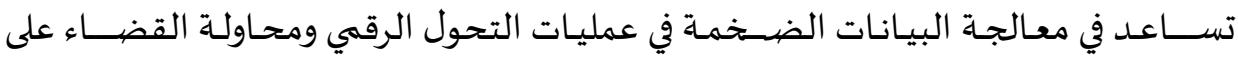

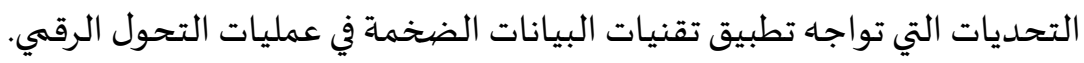
استطاع (Zhang) في دراستاه عام 2020 أن يصف بشكل أساسي وبإيجاز بعض المفاهيم ذات الصلة بالتحول الرقهي للإدارة المالية للمؤسسات التقليدية في ظلامل خلفية الفية البيانات 
الضخمة، فضلًا عن تحليل بعض الفرص والتحديات التي سوف تحتاج الشركات إلى مواجهتها

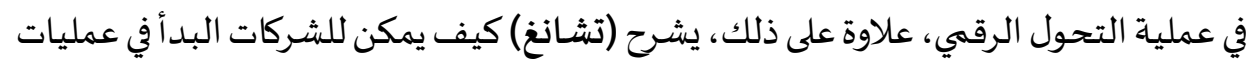

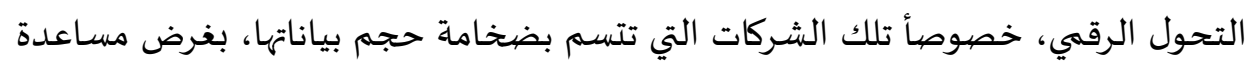
الشركات بشكل فعال على إدراك أهمية إكمال عملية التحول الرقهي في عصر البيانات الضخمة.

6. السـمات والخصــائص المميزة للإلنتـاج الفكري عن التحول الرقمي في عصــر البيانات الضخمة:

بعد استعراض الإنتاج الفكري المتعلق بموضوع التحول الرقهي في عصر البيانات الضخمة؛

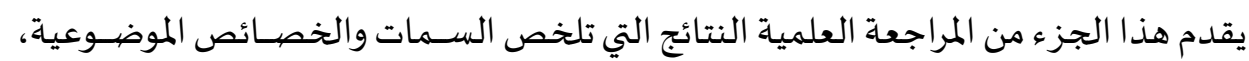

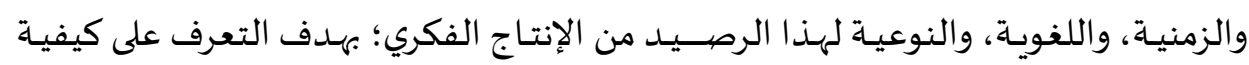
تناوله للموضوع من الناحيتين النظرية والتطبيقية.

\section{6 التطور الزمني لموضوعات الإنتاج الفكري المغطاة بالمراجعة العلمية:}

يتضـــح من خلال الجـدول (2) أن هناك فجوة بين الإنتاج الفكري باللغـة العربية والإنتاج الفكري باللغة الإنجليزية وقدرها حوالي (78\%) فيما يخص موضيـوع الدراسـة، كما يتضسح أيضـا

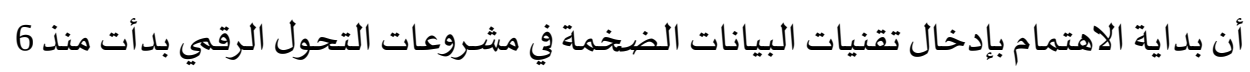
أعوام (2015).

جدول رقم (2) التوزيع اللغوي لمصهادر الإنتاج الفكري وفقًا لسنوات النشر -

\begin{tabular}{|c|c|c|c|c|c|c|c|c|c|}
\hline المئوية & المجموع & 2021 & 2020 & 2019 & 2018 & 2017 & 2016 & 2015 & التوزيع اللغوي \\
\hline \%11 & 3 & 1 & 1 & - & - & - & 1 & - & باللغة العتاج الفكرية \\
\hline$\% 89$ & 24 & 4 & 10 & 4 & 3 & 2 & - & 1 & باللغة الإنتاج الفكري \\
\hline
\end{tabular}


كمـا يبين الجـدول (3) أن الفترة الأخيرة منـذ عـام 2020 حتى الآن ازدهرت بـالإنتـاج الفكري

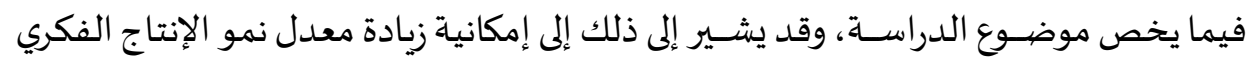
ذات العلاقة بموضوع الدراسة خلال السنوات القادمة.

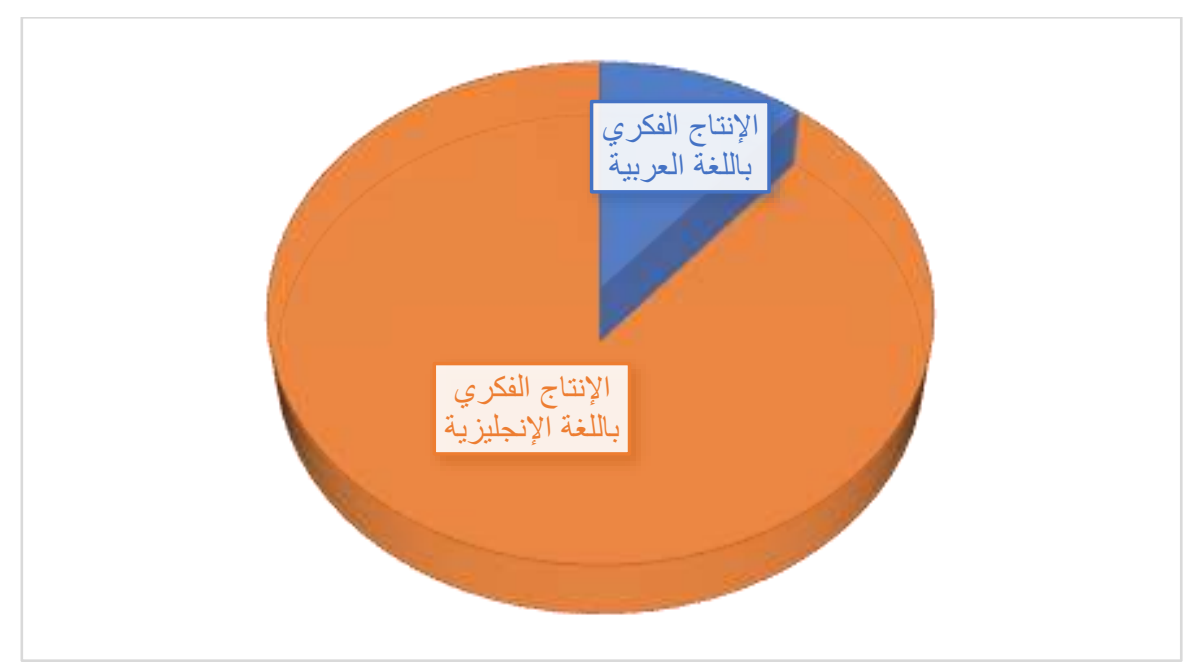

- شكل رقم (1) التوزيع اللغوي لمصيادر الإنتاج الفكري -

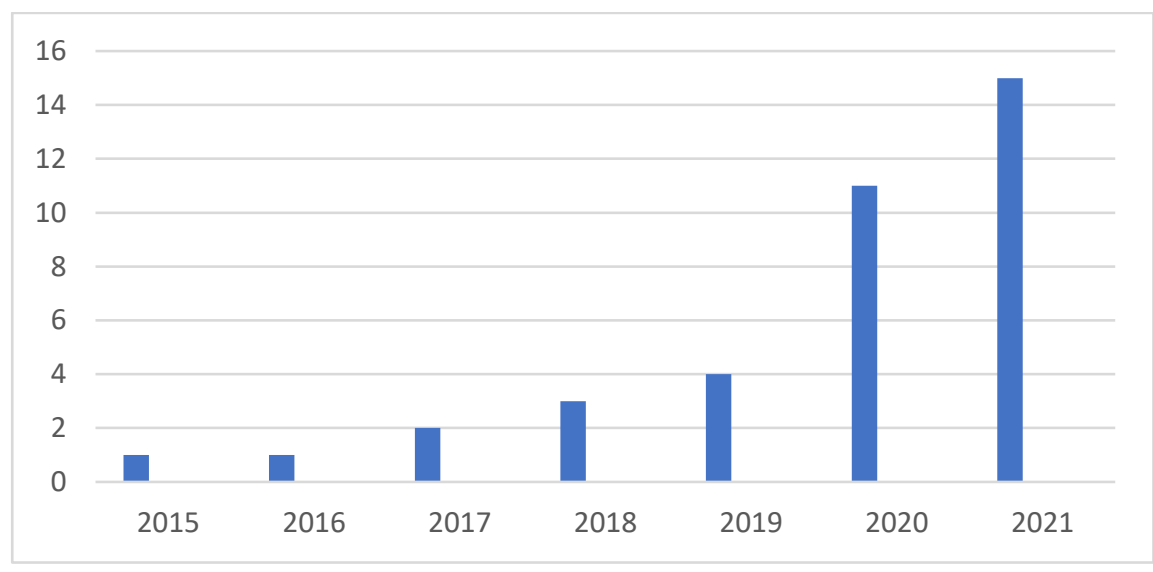

- شكل رقم (2) توزيع مصيادر الإنتاج الفكري وفقًا لسنوات النشر - 
كما يوضح الشكل (1) وجود فجوة عددية في عدد الإنتاج الفكري الصادر باللغتين العربية والأجنبية بنسبة تصل إلى 78\%، حيث نجد زيادة في اهتمامات الإنتاج الفكري الأجنبي بعمليات

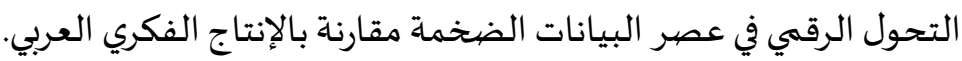

ويعرض الشكل رقم (2) توزيع مصادر الإنتاج الفكري وفقًا لسنوات النشر، حيث يوضح الشكل زيادة مستمرة في المستقبل فيما يتعلق بالإنتاج الفكري موضوفيوع الدراسـة.

2.6 السمات الموضوعية لموضيوعات الإنتاج الفكري المغطاة بالمراجعة العلمية:

يعرض الجدول رقم (3) الســمات الموضـــوعية لموضــــوعات الإنتاج الفكري المغطاة بالمراجعة

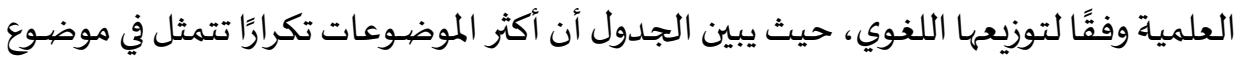

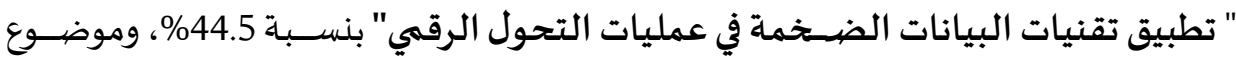

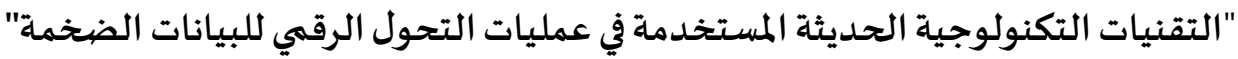

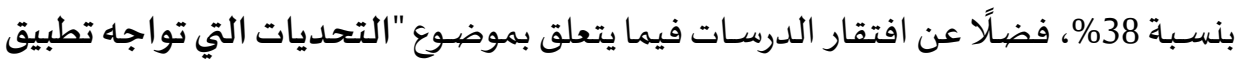

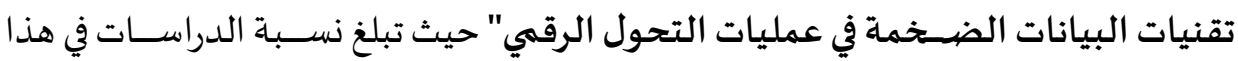

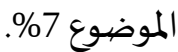

- جدول رقم (3) التوزيع اللغوي لموضوعات الإنتاج الفكري المغطاة بالمراجعة العلمية-

\begin{tabular}{|c|c|c|c|c|c|}
\hline المجموع & المئوية & الإنتاج الفكري & المئوية & الإنتاج الفكري & التوزيع الموضوعي \\
\hline 14 & \%44.5 & 12 & $\% 7$ & 2 & 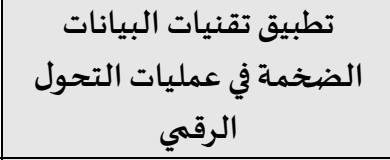 \\
\hline 11 & $\% 38$ & 10 & $\% 3,5$ & 1 & المستخدمة في عمليات التحوليات التكنولية الحديثة \\
\hline 2 & $\% 7$ & 2 & - & - & تقنيات البيانات الضحيات التي تواجه تطبيق في \\
\hline 27 & \%89.5 & 24 & $\% 10.5$ & 3 & المجموع \\
\hline
\end{tabular}




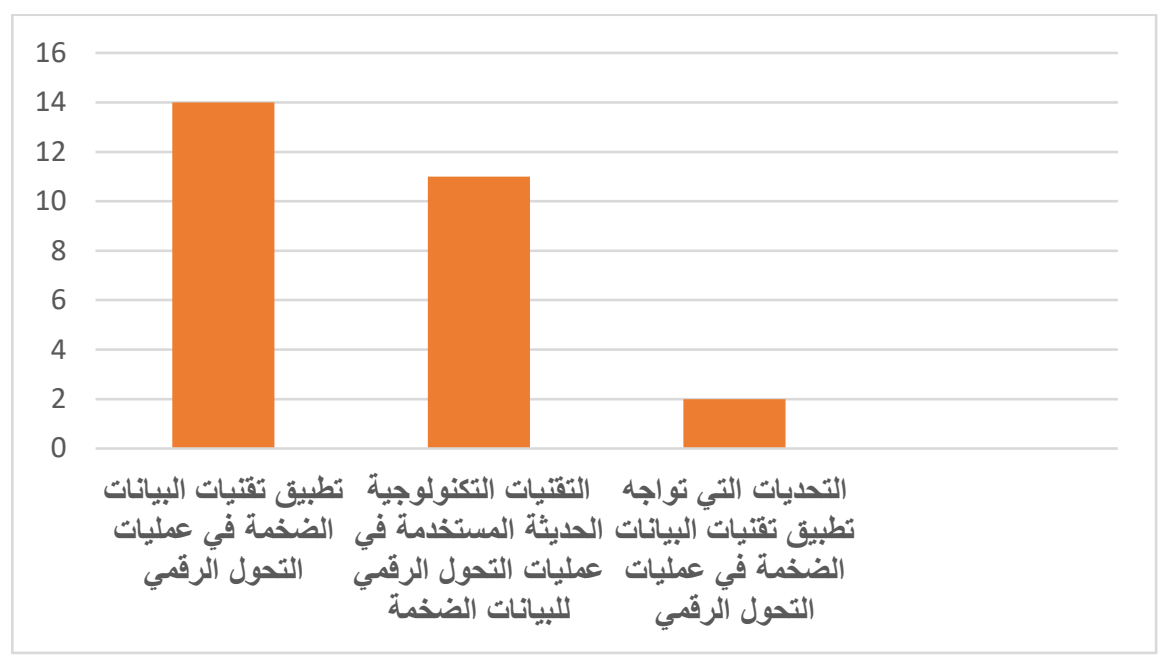

\section{شكل رقم (2) توزيع موضهوعات الإنتاج الفكري المغطاه بالمراجعة العلمية}

يعرض الثــكل (3) التوزيع الموضـــوعي للإنتـاج الفكري، حيـث يوضـــح الشــكل أن أكثر

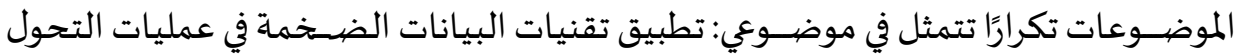

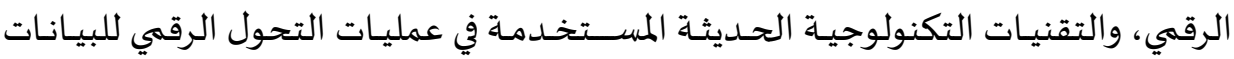
الضخمة.

3.6 السمات اللغوية لموضوعات الإنتاج الفكري المغطاة بالمراجعة العلمية: تنوع الإنتاج الفكري المنشـــور وفقًا للموضـــوعـات المغطاة بـالمراجعـة العلميـة والتي تتعلق

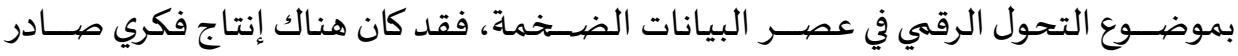

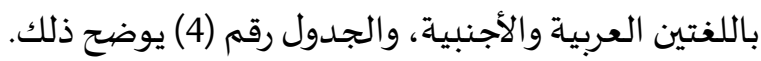

جدول رقم (4) التوزيع اللغوي للإنتاج الفكري المنشوروفقًا للموضيوعات المغطاة

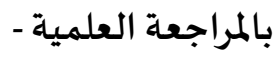

\begin{tabular}{|c|c|c|}
\hline النسبة المئوية & المجموع & الإنتاج الفكري وفقًا للتوزيع اللغوي \\
\hline$\% 11$ & 3 & الإنتاج الفكري الأجنبي \\
\hline$\% 89$ & 24 & الإنتاج الفكري العربي \\
\hline$\% 100$ & 27 & المجموع \\
\hline
\end{tabular}




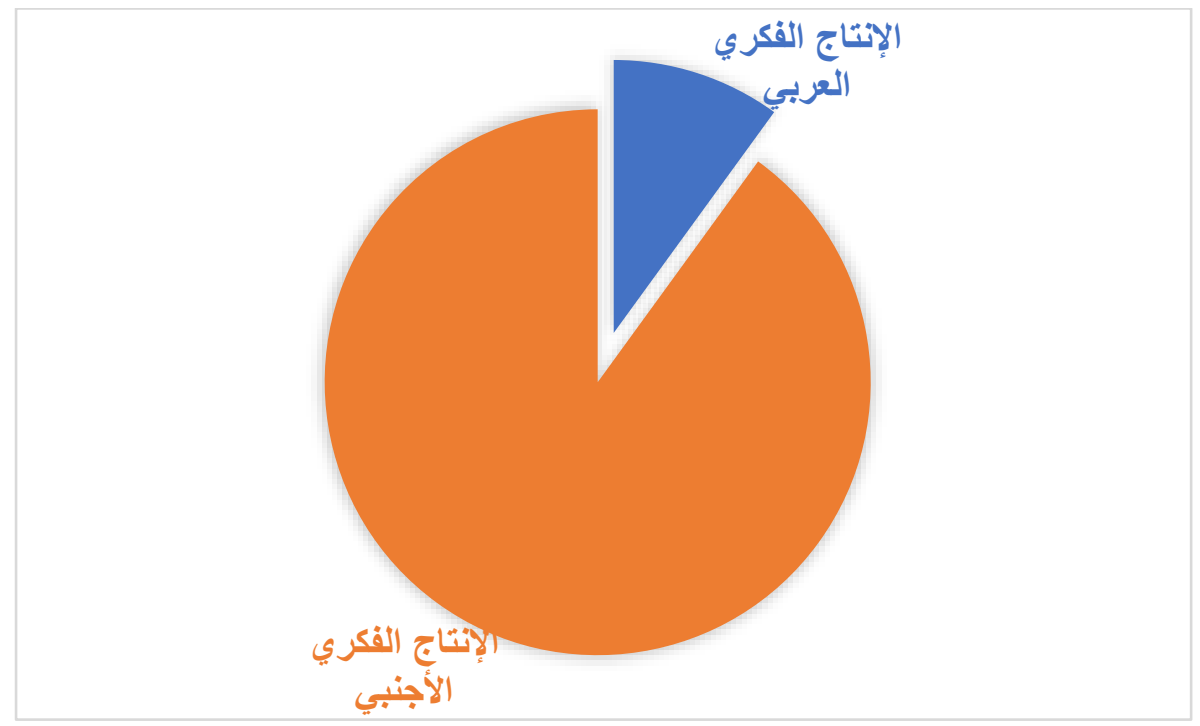

شكل رقم (3) نسب التوزيع اللغوي لإلنتاج الفكري المنشوروفقا للموضوعات المغطاة

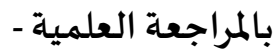

يتضح من الجدول (4) والشكل (3) أيضا التوزيع العددي والنسبي للإنتاج الفكري وفقًا

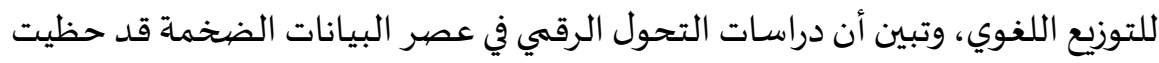

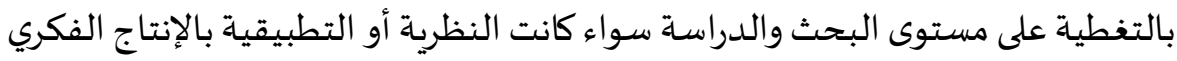
الأجنبي أكثر مما هو عليه بالإنتاج الفكري العربي، حيث تبلغ نسبة الإنتاج الفكري الأجنبي

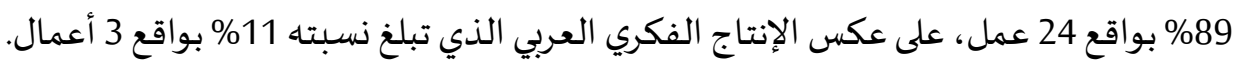

4.6 السمات النوعية لموضهوعات الإنتاج الفكري المغطاة بالمراجعة العلمية:

تتنوع فئات الإنتاج الفكري المســترجع وفقًا للموضـــوعات المغطاة بالمراجعة العلمية ما بين

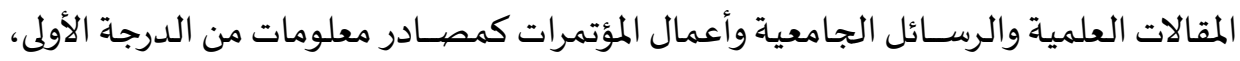

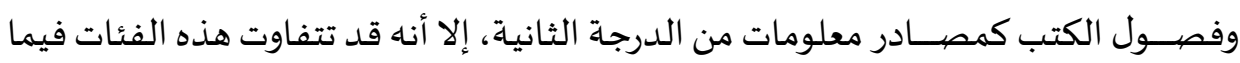

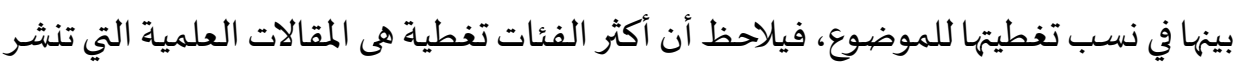
بالدوريات العلمية المتخصصية. 
جدول رقم (5) التوزيع النوعي للإنتاج الفكري وفقًا للموضوعات المغطاة بالمراجعة العلمية-

\begin{tabular}{|c|c|c|}
\hline النسبة المئوية & عدد الإنتاج الفكري المنشور & التوزيع النوعي للإنتاج الفكري \\
\hline$\% 59$ & 16 & المقالات العلمية \\
\hline$\% 18,5$ & 5 & أعمال المؤتمرات \\
\hline$\% 15$ & 4 & الرسـائل الجامعية \\
\hline$\% 7.5$ & 2 & فصيل من كتاب \\
\hline \%100 & 27 & المجموع \\
\hline
\end{tabular}

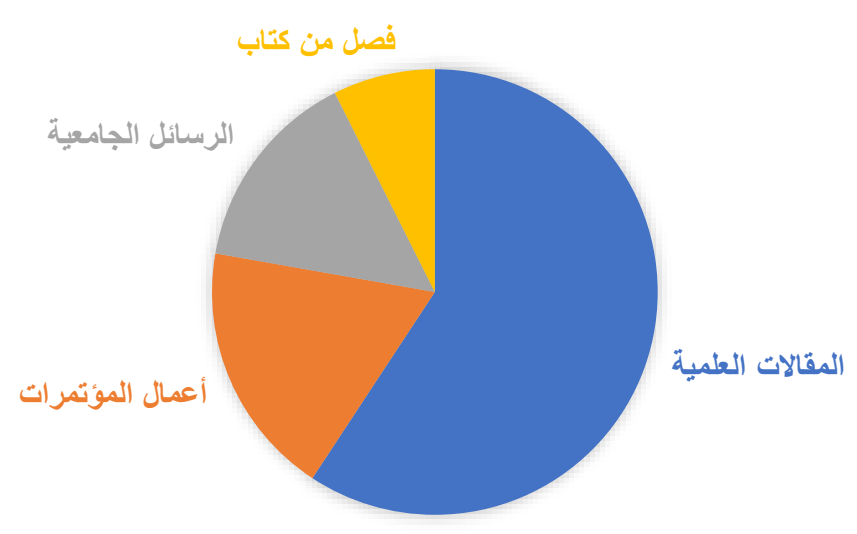

شكل رقم (4) التوزيع النوعي للإنتاج الفكري المنشوروفقًا للموضوعات المغطاه

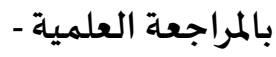

يبين الجـدول (5) التوزيع النوعي للإنتـاج الفكري وفقـا للموضــــوعـات المغطـاة بـالمراجعـة

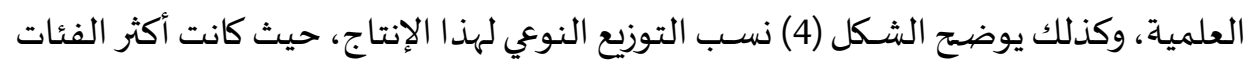

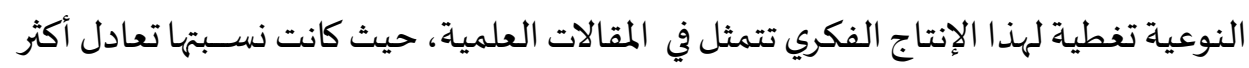

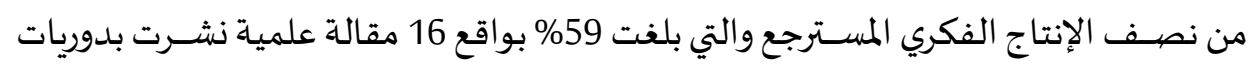

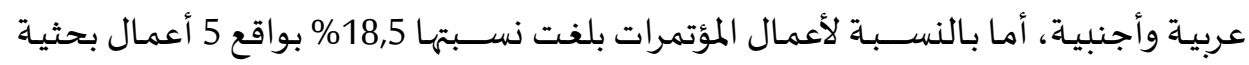
مقدمة بمؤتمرات علمية، فضيًا عن وجود رسائل جامعية أصدارتها الجامعات العبات العربية والأجنبية

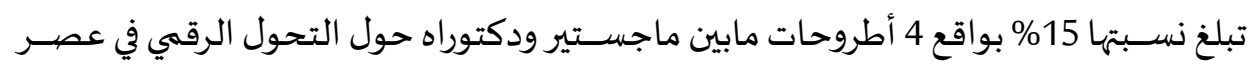


البيانات الضشخمة، وتأتي فصـول الكتب في المرتبة ألخيرة بنسـبة 7.5\% بواقع عملين فقط عن التحول الرقي في عصر البيانات الضخمة.

\section{7. الخلاصة}

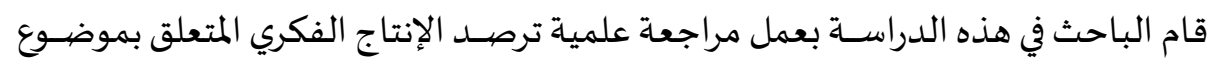
التحول الرقمي في عصر البيانات الضخمة،، والذي بلغ عدد مفرداته (27) مفردة، حيث تناولت

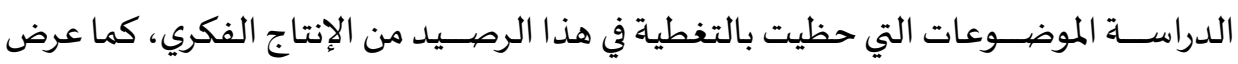
لسماته الموضوعية، والزمنية، والنوعية، واللغوية.

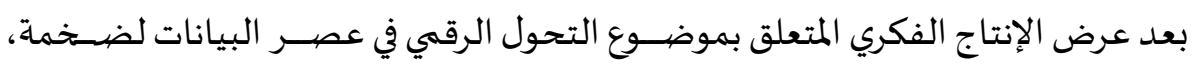
أمكن الخروج بـأن هنـاك اهتمام ملحوظ من قبـل الإنتـاج الفكري العربي والأجنبي على تنـاول

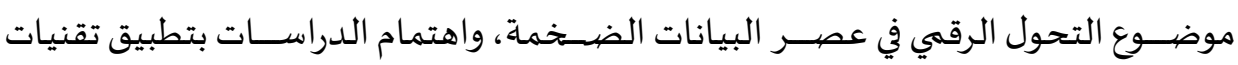

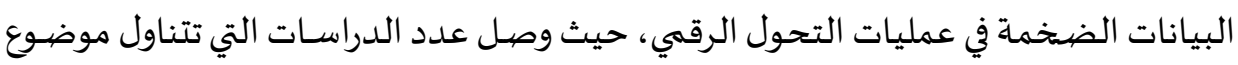
تطبيق تقنيات البيانات الضخمة في عمليات التحول الرقمي إلى (14) مفردة.

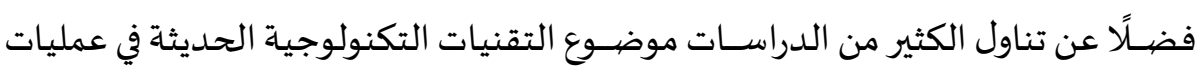

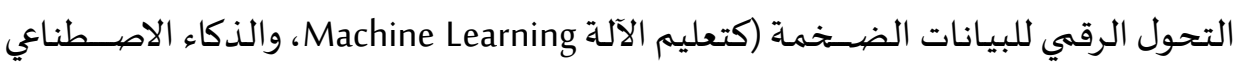
Artificial Intelligence

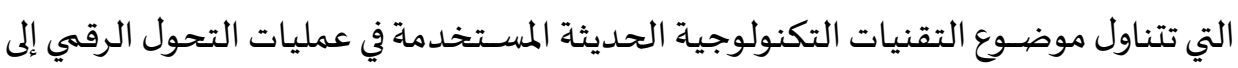
(11) مفردة.

وفي النهاية، توصـل الباحث إلى عدم وجود دراسـات كافية تتناول المشــكلات والصــعوبات

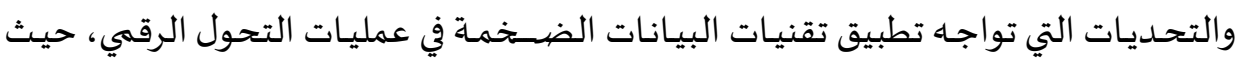

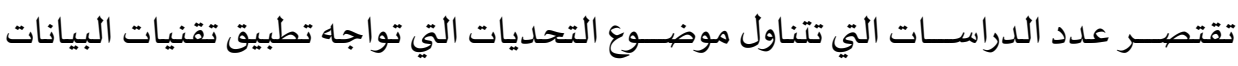

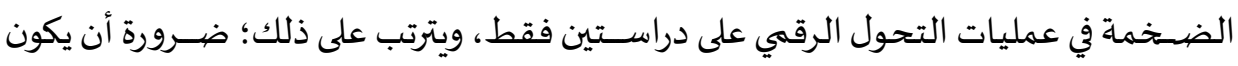
هناك المزيد من الدراسات التي تناقش قضية التحديات والمشكلات التي تواجده تطبيق التقنيات

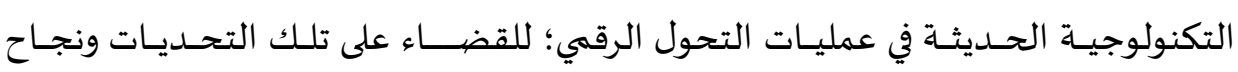

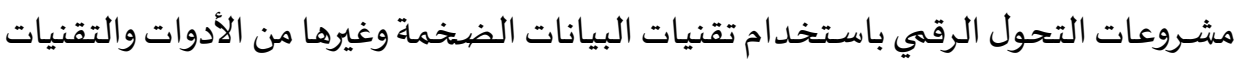

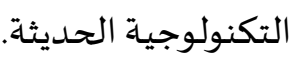


قائمة المصيادر

$$
\text { أولاً: المصيادر العربية }
$$

علي، أسـامة عبد السـلام. (2013). التحول الرقهي بالجامعات المصـرية : دراســة تحليلية. مجلة كلية التوبية. جامعة عين شمس - كلية التوبية. ع(37). ج(20).

علي، فتحي عبـدالرحيم. (2016). رقمنــة التراث العربي في مركز جمعــة المـاجــ للثقـافــة

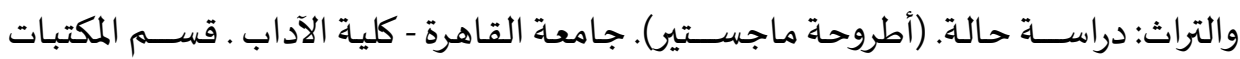
والوثائق والمعلومات دراست

مقـدمي، عبـدالرازق \& بن عمر، فـاطمـة. (2020). تحسديـات أرشـــــة البيـانـات الكبرى:

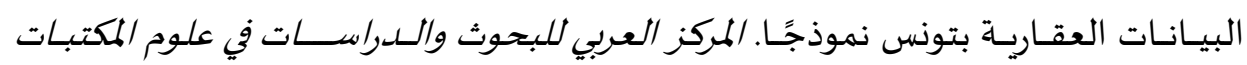
والمعلومات. مج (7). ع (14). ص: 89: 122.

نصيـر، يوسـف محمد محممد. (2021). مدى تأثير إسـتخدام البيانات الحكومية الضشخمة

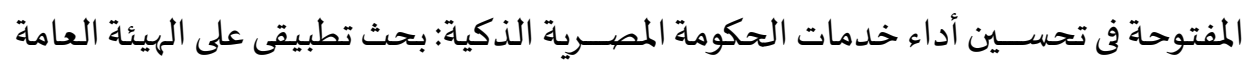

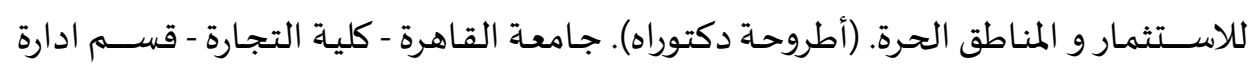

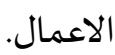

ثانيًا: المصيادر الأجنبية

Abad-Segura, E., González-Zamar, M., Infante-Moro, J., \& Ruipérez García, G. (2020). Sustainable Management of Digital Transformation in Higher Education: Global Research Trends. Sustainability, 12(5). https://doi.org/10.3390/su12052107.

Bhatti, A., Malik, H., Kamal, A., Aamir, A., Alaali, L., \& Ullah, Z. (2021). Muchneeded business digital transformation through big data, internet of things and blockchain capabilities: implications for strategic performance in telecommunication sector. Business Process Management Journal, ahead-ofprint(ahead-of-print). https://doi.org/10.1108/bpmj-12-2020-0553. 
El Hilali, W., El Manouar, A., \& Janati Idrissi, M. (2020). Reaching sustainability during a digital transformation: a PLS approach. International Journal of Innovation Science, 12(1), 52-79. https://doi.org/10.1108/ijis-08-2019-0083.

Feroz, A., Zo, H., \& Chiravuri, A. (2021). Digital Transformation and Environmental Sustainability: A Review and Research Agenda. Sustainability, 13(3), 1530. https://doi.org/10.3390/su13031530. Huang, J. (2017). Building Intelligence in Digital Transformation. Journal Of Integrated Design and Process Science, 21(4), 1-4. https://doi.org/10.3233/jid2018-0006.

Huang, J. (2019). Leveraging Big Data and Machine Learning for Digital Transformation. Journal Of Integrated Design and Process Science, 23(3), 1-3. https://doi.org/10.3233/jid190020.

Johanes, P., \& Thille, C. (2019). The heart of educational data infrastructures = Conscious humanity and scientific responsibility, not infinite data, and limitless experimentation. British Journal of Educational Technology, 50(6), 2959-2973. https://doi.org/10.1111/bjet.12862.

Khanna, V. (2020). Applications of Big Data Analytics: A Boon for the Food Industry. Application Of Big Data And Business Analytics, 79-101. https://doi.org/10.1108/978-1-80043-884-220211006.

Liu, Y., Wang, W., \& Zhang, Z. (2020). The dual drivetrain model of digital transformation: role of industrial big-data-based affordance. Management Decision, ahead-of-print(ahead-of-print). https://doi.org/10.1108/md-12-20191664

Loebbecke, C., \& Picot, A. (2015). Reflections on societal and business model transformation arising from digitization and big data analytics: A research 
التحول الرقمي في عصر البيانات الضخمة: مراجعة علمية

agenda. The Journal Of Strategic Information Systems, 24(3), 149-157.

https://doi.org/10.1016/j.jsis.2015.08.002.

Manyika, J., et al \& McKinsey Global Institute. (2011). "Big data: The next frontier for innovation, competition, and productivity". Available at: www.mckinsey.com/mgi/publications.

Mendonça, C., Andrade, A., \& Sousa Neto, M. (2018). Uso da loT, Big Data e inteligência artificial nas capacidades dinâmicas. Revista Pensamento Contemporâneo Em Administração, 12(1), 131.

https://doi.org/10.12712/rpca.v12i1.1120

Miklosik, A., \& Evans, N. (2020). Impact of Big Data and Machine Learning on

Digital Transformation in Marketing: A Literature Review. IEEE Access, 8, 101284101292. https://doi.org/10.1109/access.2020.2998754.

Odlis (Online Dictionary of Library and Information Science) Dictionary Retrieved 3-6-2021 from: https://products.abc-clio.com/ODLIS/odlis_b.aspx. Ordóñez de Pablos, P., \& Labra Gayo, J. (2019). Rethinking key issues for understanding the new challenges of disruption and digital transformation in companies and economies. Behaviour \& Information Technology, 38(9), 873-875. https://doi.org/10.1080/0144929x.2019.1641663.

Ratten, V. (2020). Digital Transformation in Sport and Social Media. Sport Startups: New Advances In Entrepreneurship, 89-104. https://doi.org/10.1108/978-1-78973-081-420201007.

Ruchi, S., \& Srinath, P. (2018). Big Data Platform for Enterprise project management digitization using Machine learning. 2018 Second International Conference on Electronics, Communication and Aerospace Technology (ICECA). https://doi.org/10.1109/iceca.2018.8474799. 
Sarker, M., Wu, M., \& Hossin, M. (2018). Smart governance through bigdata:

Digital transformation of public agencies. 2018 International Conference on Artificial Intelligence and Big Data (ICAIBD).

https://doi.org/10.1109/icaibd.2018.8396168.

Șerban, R. (2017). The Impact of Big Data, Sustainability, and Digitalization on Company Performance. Studies In Business and Economics, 12(3), 181-189. https://doi.org/10.1515/sbe-2017-0045.

Sesana, M., \& Bardelli, A. (2021). Building Digital Transformation to improve NGCTR design and simulation. IOP Conference Series: Materials Science And Engineering, 1024. https://doi.org/10.1088/1757-899x/1024/1/012103.

Sestino, A., Prete, M., Piper, L., \& Guido, G. (2020). Internet of Things and Big Data as enablers for business digitalization strategies. Technovation, 98, 1-9. https://doi.org/10.1016/j.technovation.2020.102173 Sestino, A., Prete, M., Piper, L., \& Guido, G. (2020). Internet of Things and Big Data as enablers for business digitalization strategies. Technovation, 98, 1-9.

https://doi.org/10.1016/j.technovation.2020.102173.

Thamjaroenporn, P., \& Achalakul, T. (2020). Big Data Analytics Framework for Digital Government. 2020 1St International Conference on Big Data Analytics And Practices (IBDAP). https://doi.org/10.1109/ibdap50342.2020.9245461.

Zhang, M. (2020). Exploration of the Digital Transformation of Traditional Enterprise Financial Management under the Background of Big Data. 2020 International Conference On Big Data Economy And Information Management (BDEIM). https://doi.org/10.1109/bdeim52318.2020.00009. 